\title{
WestVirginiaUniversity
}

THE RESEARCH REPOSITORY @ WVU

Graduate Theses, Dissertations, and Problem Reports

2010

\section{Assessing the variation of driver distraction with experience-- Research extension}

Pradeep Thummala

West Virginia University

Follow this and additional works at: https://researchrepository.wvu.edu/etd

\section{Recommended Citation}

Thummala, Pradeep, "Assessing the variation of driver distraction with experience--- Research extension" (2010). Graduate Theses, Dissertations, and Problem Reports. 3306.

https://researchrepository.wvu.edu/etd/3306

This Thesis is protected by copyright and/or related rights. It has been brought to you by the The Research Repository @ WVU with permission from the rights-holder(s). You are free to use this Thesis in any way that is permitted by the copyright and related rights legislation that applies to your use. For other uses you must obtain permission from the rights-holder(s) directly, unless additional rights are indicated by a Creative Commons license in the record and/ or on the work itself. This Thesis has been accepted for inclusion in WVU Graduate Theses, Dissertations, and Problem Reports collection by an authorized administrator of The Research Repository @ WVU. For more information, please contact researchrepository@mail.wvu.edu. 


\title{
ASSESSING THE VARIATION OF DRIVER DISTRACTION WITH EXPERIENCE - RESEARCH EXTENSION
}

\author{
Pradeep Thummala
}

\author{
Thesis submitted to the \\ College of Engineering and Mineral Resources \\ at West Virginia University \\ in partial fulfillment of the requirements \\ for the degree of
}

\author{
Master of Science \\ in \\ Civil Engineering
}

Leonel Medellin, Ph.D., Chair

David R. Martinelli, Ph.D.,

Avinash Unnikrishnan, Ph.D.

\section{Department of Civil \& Environmental Engineering \\ Morgantown, West Virginia \\ 2010}

Keywords: driver distraction, experience, novice, eye tracking, eye glance, young 


\section{ASSESSING THE VARIATION OF DRIVER DISTRACTION WITH EXPERIENCE, RESEARCH EXTENSION \\ PRADEEP THUMMALA \\ ABSTRACT}

Deviating attention from the complex task of driving can be distraction. Driving requires the scanning of the road environment (front, sides and back), as well as monitoring dashboard and navigational tools. Shorter eye glance durations away from road are used for better scanning of roadside hazards, compared to longer eye glances that are riskier and considered distraction.

Defining distraction as looking away from roadway for more than 2 seconds, this research analyses eye glances away from roadway for more than 2 seconds, 2.5 seconds and 3 seconds using variables such as total glance duration away from roadway, percentage glance duration away from roadway and number of glances away from roadway using data collected from young, novice and experienced drivers.

This research compares young, novice and experienced drivers, as well as first 6 months, next 6 months of novice licensed drivers by statistical analysis. It is found that novice drivers exhibit significant difference with experienced drivers and young or GDL (graduate driver license) drivers behave as experienced in presence of an instructor. No significant difference was found in eye glance characteristics of drivers within first 6 months (0-6 months) and next 6 months of license (7-12 months). 


\section{ACKNOWLEDGEMENTS}

I would like to gratefully acknowledge the enthusiastic supervision of Dr. Leonel Medellin, a great teacher and advisor who was abundantly helpful and offered invaluable assistance, support and guidance to accomplish this research project.

I wish to thank Dr. David R. Martinelli for giving me the financial support and Dr. Avinash Unnikrishnan, for his valuable suggestions during analysis of results and I thank both for their comments on my thesis.

I would also acknowledge my family members for their encouragement. Especially my father, Mr. T. Purushothama Naidu and my mother Mrs. Drakshayani and my dearest friends, for their valuable support at all times.

Finally, I am grateful to MAUTC and WVDOH for funding this research. 


\section{TABLE OF CONTENTS}

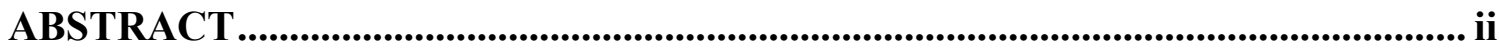

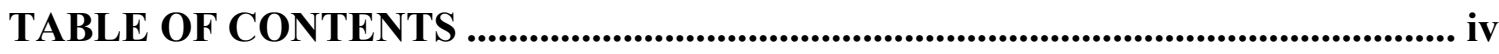

LIST OF TABLES ................................................................................................ vi

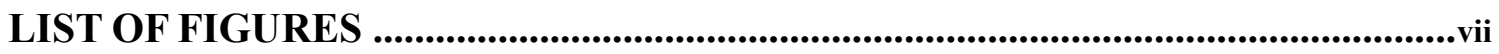

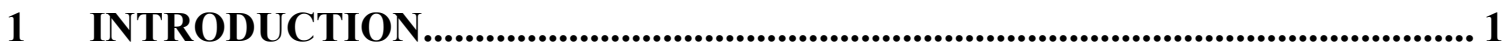

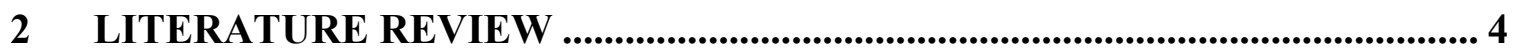

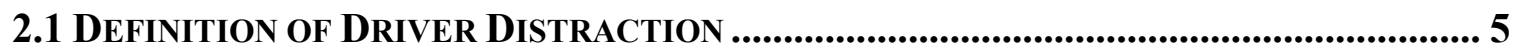

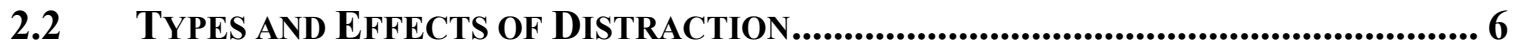

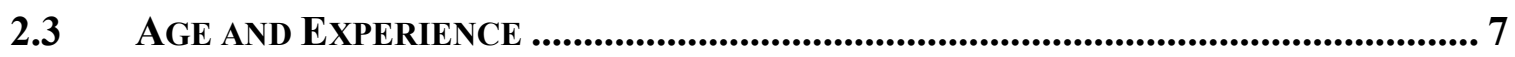

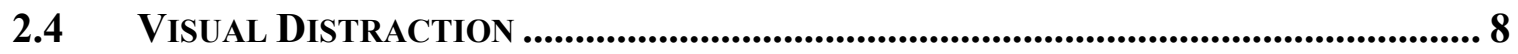

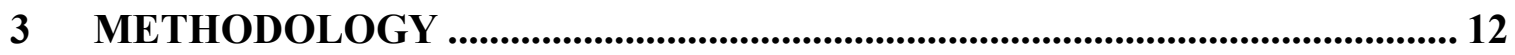

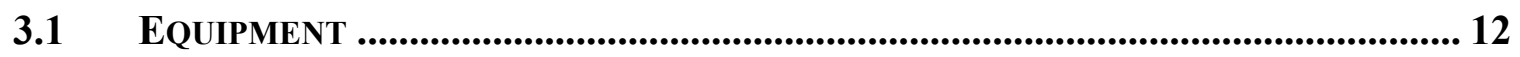

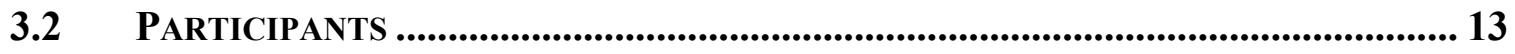

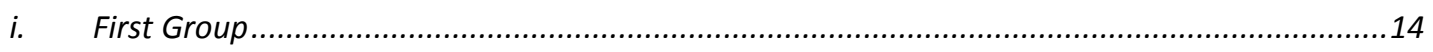

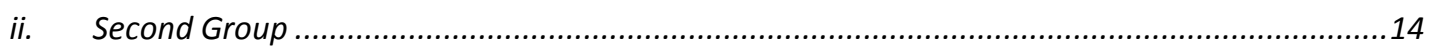

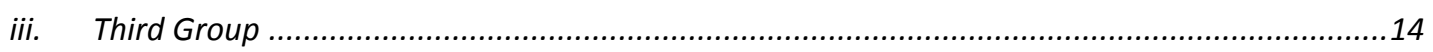

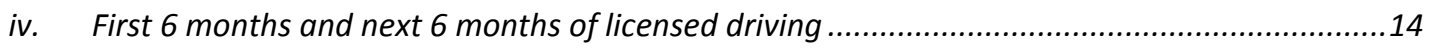

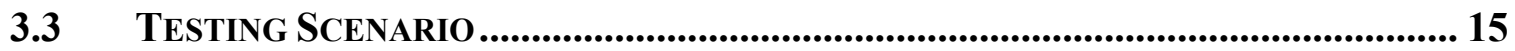

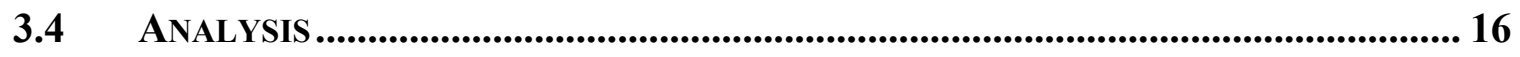

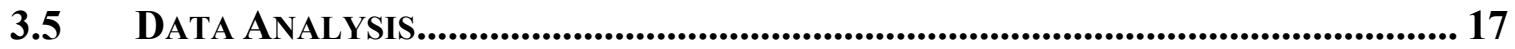


4 RESULTS .

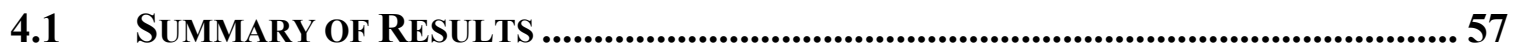

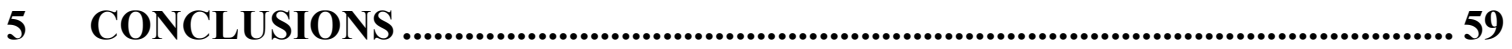

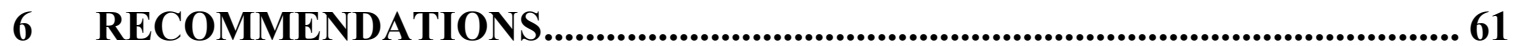

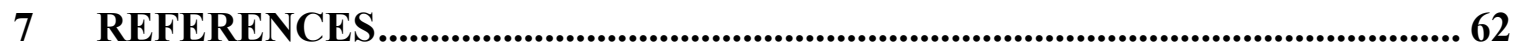




\section{LIST OF TABLES}

Table 1: Sources of distraction ........................................................................ 6

Table 2: Types of distraction and percentage of drivers involved ................................. 6 


\section{LIST OF FIGURES}

Figure 1: Total glance duration, 2 or more sec/glance, groups (1) \& (3) ............................... 21

Figure 2: Total glance duration, 2 or more sec/glance, groups (2) \& (3) ................................. 22

Figure 3: Total glance duration, 2 or more sec/glance, groups (1) \& (2) ................................ 23

Figure 4: Total glance duration, 2 or more sec/glance, Novice drivers with first 6 months and next 6 months after license ........................................................................ 24

Figure 5: Total glance duration, 2.5 or more sec/glance, groups (1) \& (3) ............................ 25

Figure 6: Total glance duration, 2.5 or more sec/glance, groups (2) \& (3) ............................ 26

Figure 7: Total glance duration, 2.5 or more sec/glance, groups (1) \& (2) ........................... 27

Figure 8: Total glance duration, 2.5 or more sec/glance, Novice drivers with first 6 months and

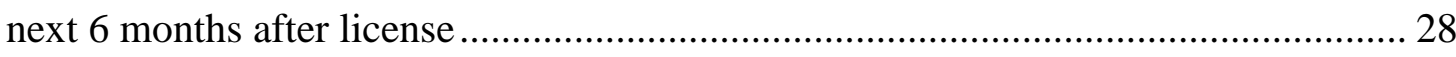

Figure 9: Total glance duration, 3 or more sec/glance, groups (1) \& (3) .............................. 29

Figure 10: Total glance duration, 3 or more sec/glance, groups (2) \& (3) ............................... 30

Figure 11: Total glance duration, 3 or more sec/glance, groups (1) \& (2) ............................. 31

Figure 12: Total glance duration, 3 or more sec/glance, Novice drivers with first 6 months and

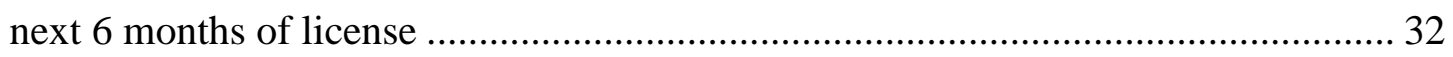

Figure 13: Percentage time looking away from roadway, 2 or more sec/glance, groups (1) \& (3)

Figure 14: Percentage time looking away from roadway, 2 or more sec/glance, groups (2) \& (3)

Figure 15: Percentage time looking away from roadway, 2 or more sec/glance, groups (1) \& (2) 
Figure 16: Percentage time looking away from roadway, 2 or more sec/glance, Novice drivers with first 6 months and next 6 months after license 36

Figure 17: Percentage time looking away from roadway, 2.5 or more sec/glance, groups (1) \& (3)

Figure 18: Percentage time looking away from roadway, 2.5 or more sec/glance, groups (2) \& (3)

Figure 19: Percentage time looking away from roadway, 2.5 or more sec/glance, groups (1) \& (2)

Figure 20: Percentage time looking away from roadway, 2.5 or more sec/glance, Novice drivers with first 6 months and next 6 months after license 40

Figure 21: Percentage time looking away from roadway, 3 or more sec/glance, groups (1) \& (3)

Figure 22: Percentage time looking away from roadway, 3 or more sec/glance, groups (2) \& (3)

Figure 23: Percentage time looking away from roadway, 3 or more sec/glance, groups (1) \& (2)

Figure 24: Percentage time looking away from roadway, 3 or more sec/glance, Novice drivers with first 6 months and next 6 months after license 44

Figure 25: Number of glances away from roadway, 2 or more sec/glance, groups (1) \& (3) ...... 45

Figure 26: Number of glances away from roadway, 2 or more sec/glance, groups (2) \& (3)..... 46

Figure 27: Number of glances away from roadway, 2 or more sec/glance, groups (1) \& (2) ..... 47

Figure 28: Number of glances away from roadway, 2 or more sec/glance, Novice drivers with first 6 months and next 6 months after license 48

Figure 29: Number of glances away from roadway, 2.5 or more sec/glance, groups (1) \& (3) ... 49 
Figure 30: Number of glances away from roadway, 2.5 or more sec/glance, groups (2) \& (3) ... 50

Figure 31: Number of glances away from roadway, 2.5 or more sec/glance, groups (1) \& (2) ... 51

Figure 32: Number of glances away from roadway, 2.5 or more sec/glance, Novice drivers with

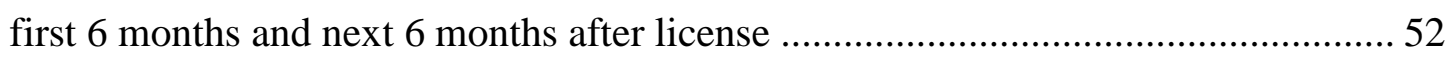

Figure 33: Number of glances away from roadway, 3 or more sec/glance, groups (1) \& (3) ...... 53

Figure 34: Number of glances away from roadway, 3 or more sec/glance, groups (2) \& (3) ...... 54

Figure 35: Number of glances away from roadway, 3 or more sec/glance, groups (1) \& (2) ...... 55

Figure 36: Number of glances away from roadway, 3 or more sec/glance, Novice drivers with first 6 months and next 6 months after license 56 


\section{INTRODUCTION}

Driving is a complex task which demands the driver to be attentive and concentrated using cognitive, physical, sensory and psychomotor skills; deviating from this condition leads to distraction (Beirness, 2001; Peters, 2001). Factors causing distraction have been studied since the 1960s, but the severity of the problem has deepened in recent years due to new in-vehicle technologies, wireless communication and complex highway infrastructure. However, it seems that no significant policy changes have been established, especially with respect to young and novice drivers. Statistics show that novice drivers get easily distracted and are involved in a high percentage of crashes.

According to the National Highway Traffic Safety Administration (NHTSA), driver distraction has been on the rise in recent years. From 2004 to 2008, traffic incidents increased from 8 percent to 11 percent due to distracted driving. In 2008, the Fatality Analysis and Reporting System (FARS) reported that more than 20 percent of incidents involved some type of distraction. Statistics reported in 2008 by NHTSA indicate that:

5,870 people died in crashes that involved distracted driving, with more than half million injured $(515,000)$.

$>21$ percent of 1,630,000 injury crashes involved distracted driving

The majority of the causes behind these incidents include using cell phones, texting while driving, eating and drinking, using in-vehicle technologies and other electronic devices. Younger, inexperienced drivers under the age of 20 occupy the highest percentage in fatal crashes caused due to distraction. They accounted for almost 16 percent of distraction-related 
fatal crashes, followed by drivers ages 20 to 29 with 12 percent. Common characteristics shown by inexperienced drivers include errors in:

- Attention

- Visual search

- Speed relative to conditions

- Emergency maneuvers with high speeds and risky behavior

Among the above errors, visual search plays an important role for the driving task to be accomplished. This is because the other distractions can be controlled by effectively implementing countermeasures, but visual search is affected by secondary tasks (i.e. using wireless devices, in-vehicle navigational equipment, eating, drinking, smoking, looking outside objects). The incidence of decreased visual search while performing secondary tasks is higher among novice drivers compared to experienced drivers, mainly due to lack of experience (Trent, 2005).

The visual search behavior is studied by analyzing eye glances. Previous studies on eye glances were performed using a video recorder. The video tapes were analyzed frame-by-frame to get glance data (Farber, 2000). Recent technologies, however, track real-time eye and head movements by measuring frequency and duration of eye glances. Developed by Volvo and Seeing Machines, FaceLAB is one such new technology that employs a video-based tracking system to measure visual behavior (www.seeingmachines.com)

The first part of this research, "Assessing the Variation of Driver Distraction with Experience" (Akuraju, 2009), consisted of scanning and studying patterns among novice and experienced drivers in a real-life environment. From the study, it was found that experienced 
drivers exhibit better scanning behavior than novice drivers. On the other side, novice drivers concentrate on center of the road without efficiently scanning surrounding hazards (Akuraju, 2009).

Eye glance studies have measured the time when driver eyes are off the center of the road by calculating the time to accomplish non-driving tasks; this is a widely accepted and valid measure of the visual demand (Curry, 2002; Haigney \& Westerman, 2001). "A second conclusion of this work was the demonstration that visual allocation measures, including glance duration, number of glances and total glance time away from the road scene can be used to assess the driver's workload associated with in-cab devices" (Ranney, 2000).

This research, "Assessing the Variation of Driver Distraction with Experience, Research Extension", makes use of the same data collected with FaceLAB equipment and studies eye glance patterns among young, novice and experienced drivers. Eye glance measurements reveal the extent to which a driver is distracted. Given that the data used in this analysis was collected in a real-life driving condition, distraction measurements represent actual-driving visual behavior. This research determines a) total time duration eyes are off the roadway, b) number of glances away from roadway, and c) percentage time distracted, and compares significant differences among young, novice and experienced drivers. In addition, this research tries to find differences among novice drivers with in first 6 months and next 6 months of licensure. 


\section{LITERATURE REVIEW}

"Driving is a self paced task in which drivers make the task more or less complicated depending on their chosen margins of error" (Elander, 1993). Driving is a task that requires continuous execution of physical, cognitive, and sensory skills. Drivers applying multiple skills in order to drive, and furthermore, engaging in other non-driving related tasks are lead to inattention. Wickens multiple resource theory states that parallel performance of two tasks results in task interference due to demands for same skills (Wickens, 2002). When driving, any activity that competes for the driver's attention has the potential to degrade performance and have serious consequences.

When involved in secondary tasks, drivers are often unaware of its consequences, undermine risks, and endanger themselves (Lesch \& Hancock, 2004; White, 2004). The pressure of a non-driving task on driving is determined by the complexity of the task, the situational driving demands, and the experience to handle the task (Young \& Regan, 2003). This situation, when driving is affected by non-driving tasks, is called driver inattention. Crash rates, due to driver inattention, decrease with age and experience up to a point; then increase again as drivers get older. Younger drivers tend to pull into narrow gaps in traffic, travel with shorter following distances, and drive faster (Bottom \& Ashworth, 1978; McKenna, 1998; Galin, 1981; Quimby \& Watts, 1981; Baxter et al, 1990; Evans \& Wasielewski, 1983). The "100-Car Naturalistic Study" conducted by VTTI found that driver inattention was the cause of 80 percent of crashes and 65 percent of near crashes. 
Driver inattention can be divided into four categories:

1. Engaging in secondary tasks

2. Fatigue

3. Inattention towards roadway

4. Non-specific eye glances

This review discusses frequent definitions of distraction found in the literature, followed by the types and effects of distraction. Given that young, novice drivers account for the highest crash rates, common characteristics of inexperienced drivers are reviewed next. As mentioned previously, driving is basically a visual task, for that reason visual distraction is examined afterward. Finally, some commonly used methods to measure visual distractions and counter measures to reduce visual distractions are assessed (Neale et al, 2005).

\subsection{Definition of Driver Distraction}

A standard definition for driver distraction has not been agreed upon by researchers due to the complexity evolving around the events or objects that divert attention from driving. However, most definitions identify it as a delay in recognizing information needed to drive safely due to interference by an event, an object or a person in the vehicle or out of the vehicle (Treat, 1980). It is a shift in attention from stimuli critical in driving to stimuli not related to driving (Streff \& Spradlin, 2000). Regan et al provides a table showing various forms of distraction depending on the source of distraction (Reagan et al, 2009). 
Table 2.1: Sources of distraction

\begin{tabular}{|l|l|l|l|l|}
\hline Source & $\begin{array}{l}\text { Location of } \\
\text { Source }\end{array}$ & Intentionality & Process & Outcome \\
\hline Object & $\begin{array}{l}\text { Internal } \\
\text { activity }\end{array}$ & $\begin{array}{l}\text { Compelled by } \\
\text { source }\end{array}$ & $\begin{array}{l}\text { Disturbance of } \\
\text { control }\end{array}$ & Delayed response \\
\hline Person & Inside vehicle & Driver's choice & $\begin{array}{l}\text { Diversion of } \\
\text { attention }\end{array}$ & $\begin{array}{l}\text { Degraded longitudinal \& } \\
\text { lateral control }\end{array}$ \\
\hline Event & $\begin{array}{l}\text { Outside } \\
\text { vehicle }\end{array}$ & $\begin{array}{l}\text { Misallocation of } \\
\text { attention }\end{array}$ & $\begin{array}{l}\text { Diminished situation } \\
\text { awareness }\end{array}$ \\
\hline Activity & & & $\begin{array}{l}\text { Degraded decision-making, } \\
\text { increased crash risk }\end{array}$ \\
\hline
\end{tabular}

(Source: Regan et al, 2009)

The table explains the location, behavior and effects of distraction among drivers depending on different sources of distraction.

\subsection{Types and Effects of Distraction}

Stutts and other researchers conducted a study using crash data collected from 1995 to 1999. He found that 8.3 percent of crashes were caused due to driver being distracted by an object, a person or an event in or out of the vehicle (Stutts et al, 2001). Driver-distracted crashes were studied to find the actual cause behind distraction. The following factors were found:

Table 2.2: Types of distraction and percentage of drivers involved

\begin{tabular}{|l|c|}
\hline Type of Act & $\begin{array}{c}\text { Percentage of } \\
\text { Drivers }\end{array}$ \\
\hline Outside the vehicle & 29.4 \\
Adjusting radio, cassette or & 11.4 \\
CD Player & 10.9 \\
Tailgating & 1.5 \\
Using cell phone & \\
\hline
\end{tabular}

(Source: Stutts et al, 2001) 
Glaze and Ellis used data collected in 2002 by state troopers in the Commonwealth of Virginia and found some interesting facts. Their conclusions were entirely different from those of Stutts. According to them, passengers in vehicles represent the highest percentage of distraction, followed by adjusting radio, cassette or CD player, eating/drinking, using cell phones, adjusting vehicle controls, etc. Other non-classified distractions inside the vehicle occupied most of the distraction factors (Glaze \& Ellis, 2003).

Presence of passengers in the vehicle increased the response times needed to avoid pedestrians and the difficulty to maintain speed and lane during complex situations (Laberge et al, 2003). Distraction varied depending on different driving environments, according to a study using twelve participants conducted by Liu. The participants drove on both urban roads and freeways and Liu concluded that drivers were more distracted on urban roads. This is because complex driving environments increase workload when involved in secondary tasks (Liu \& Lee, 2006).

\subsection{Age and Experience}

In assessing driver distraction among experienced and novice drivers, previous research found that experienced ones scan surroundings more often, while novice and young drivers look mostly at center of the roadway unaware of roadside and lateral hazards (Akuraju, 2009). Crash analysis of drivers 17 to 25 shows voluntary risky behavior such as failure to detect potential hazards (Clarke et al, 2005). They have a modest ability to assess hazards in traffic such as timely noticing vehicles ahead of them (Brown \& Groeger, 1988; McKnight \& McKnight, 2000).

The risk of young drivers' unaware of risky situations and ease of distraction is considerably higher than the risks associated with not using a seat belt, driving at night, or 
driving with the presence of other teenage passengers in the car. Furthermore, driving inattention is four times higher in younger drivers compared to experienced drivers (Hedlund et al, 2003; Lin \& Fearn, 2003). The inattention is measured among 18 to 20 year old inexperienced drivers in the 100- Car Naturalistic Study, where the drivers misjudged situations by:

1. Involving in secondary tasks at high risk situations

2. Driving while impaired

3. Other aggressive driving practices

McKnight \& McKnight, in a study investigating 2000 accidents involving drivers between ages 16 to 19 in non-fatal accidents, found significance in errors related to attention, visual search, high speeds, unable to recognize hazards, and making emergency maneuvers. The differences in type of errors were minimal among first year novices and experienced youth (McKnight \& McKnight, 2003).

\subsection{Visual Distraction}

Driving is primarily a visual task; therefore the study of visual distraction is important. Some researchers identify three types of prominent visual distractions (Ito 2001):

1. Driver's sight is blocked by objects, such as stickers on windscreen or dark window tints, preventing driver from recognizing hazards

2. Looking at other in-vehicle or external objects for an extended period of time

3. Loss of visual attentiveness also called as "looked but didn't see"

Young found that, out of the above 3 types of visual distractions, the second one is more noteworthy because it indicates the characteristics of distracted driving and appealing for 
research (Young, 2003). According to researchers on this topic, looking away from the roadway for more than two seconds is considered a distraction (Rockwell, 1988; Zwahlen, 1988). When a glance away from the roadway lasts for two or more seconds, the influence of a non-driving task increases on driving (Trent et al, 2005).

The drivers' ability to keep the vehicle in lane and respond to leading vehicles on-time diminishes when they look away from the road for a considerable amount of time (Lamble et al, 1999; Senders et al, 1967). Young and novice drivers do not have the required experience needed to process visual information when engaged in secondary tasks. Difficulty in processing visual information is due to their different visual fixation and scanning patterns (Mourant \& Rockwell, 1972). The novice drivers fail to detect high risk situations due to their different visual behavior (Pradhan et al, 2005).

Crundall experimented with a group of 40 drivers consisting of experienced and novice drivers, and another group of 20 non-drivers, to find out difference in peripheral vision among them. The experiments were conducted by showing them several hazard situations and rate them on a scale of 1 to 7 . They concluded that as the visual demand at a particular point of fixation increases, the drivers lose attention depending on experience (Crundall et al, 1999).

New licensed drivers tend to look only at center of the road without scanning for side hazards or focusing on a secondary task for long periods of time, therefore neglecting the road environment (Akuraju, 2009). However, there is little change in their scanning patterns during the first six months after driver licensing, when glances at the left view mirror start being observed (Olsen et al, 2007). 
Visual distraction is measured by employing techniques such as peripheral detection task, visual occlusion technique and eye glance studies. A driver's visual behavior can be studied by recording and measuring the frequency and duration of eye glances away from the center of the roadway. This is a valid measure to evaluate the distraction caused by secondary tasks (Dewar \& Olson, 2001; Curry et al, 2002; Haigney et al, 2001; Farber et al, 2000). Studies can be conducted on simulated or real life environments.

In a study involving six drivers on a freeway, Brackstone \& Waterson found that drivers spend 80 percent of their time looking towards the roadway with variations in their fixations depending on road sections (Brackstone \& Waterson, 2003). Drivers are more distracted towards active signs and movable displays which receive longer glance durations and a higher number of glances than normal advertising signs (Beijer, 2003). A similar study found that drivers get more distracted when advertising signs are in line of sight, receiving an increased number of glances and glance duration (Smiley et al, 2003).

Donmez used an eye tracker, called FaceLAB 4.2, mounted on a simulator and studied the eye glance behavior of drivers ages 18 to 21 . He found that drivers with longer glance duration exhibit worse driving performance than those with shorter glance duration (Donmez et al, 2010). Novice drivers were found to have longer glance duration, of more than 3 seconds, compared to experienced drivers whose glance durations did not exceed 3 seconds, when managing secondary tasks (Wikman et al, 1998). After driving neighborhood and freeway routes, Mourant found that glances of novice drivers were restricted to smaller areas and glancing towards mirrors was less frequent compared to experienced drivers (Mourant \& Rockwell, 1972). 
Distraction is caused due to the driver's inability to perform the driving task without involving in any other secondary tasks. This characteristic is most commonly found in young and novice drivers due to lack of experience. Experienced drivers are able to allocate sufficient time to perform the primary task of driving, when involved in a secondary task. Increase in wireless and navigational device usage has become main cause of distractions now a days, compared to previous decade.

Visual behavior is an important part of the driver's ability to better scan roads and look out for hazards. Novice drivers tend to focus on center of roadway, scan shorter distances and exhibit long duration glances off the road. On the other side, experienced drivers scan a larger part of the roadway and make a higher number of shorter glances (Akuraju, 2009). Regarding the test scenario, real world, on-road or on-track studies provide more standardized results than simulated environments (Bach et al, 2001).

Eye glance studies are considered to be a more reliable form of measuring distraction. This can be used in finding the number of glances and time required for each distracting task by employing an eye tracker equipment that measures glance durations. 


\section{METHODOLOGY}

Visual behavior is one of the most important characteristics among drivers given that driving is primarily a visual task. This behavior is disturbed by factors in and out of vehicle such as billboards, highway incidents, on-road objects, and in-vehicle factors (i.e. passengers, cell phone, navigational devices, etc.). Young, novice drivers are prone to distraction mainly due to lack of experience and age.

In this research, distraction is determined by considering the "direction of eye gaze" (or glance), when gaze is positioned on a point other than center of roadway or side/rear view mirrors for a relatively long period of time. In previous phase of this research, looking away from the roadway for 2 seconds was considered enough for safely scanning surroundings while more than 2 seconds was considered distraction.

In this research extension, the definition of distraction will vary the time period that describes it as distraction. Driver distraction will be considered as "not looking at the center of the roadway or mirrors for more than $2.0,2.5$ or 3.0 seconds". From data collected, if the gaze is away from the center of roadway for a period longer than 5 seconds, the driver is considered to be at a traffic signal or in a queue and the gaze is not considered for analysis. The complete experimental setup is described as follows.

\subsection{Equipment}

As stated above, driving is mostly a visual task and requires considerable attention to see roadway and scan surroundings with the help of side and rear view mirrors. Deviating from the above task leads to distraction. Therefore, in order to study the visual behavior, an eye tracking 
equipment called FaceLAB version 4.5 is used to record eye movements. The equipment consists of a set of two small cameras placed on vehicle dashboard that tracks the driver's eye and head movements. It enables real time analysis of eyelid movements, head pose and gaze direction; it also records blinking and eye closure of driver's eyes. Actual measurements are based on the position of eyelid rather than brightness of the eye or percent of eye closure.

Eye tracking is performed by creating planes in the computerized model that represent the center of roadway, rearview and side mirrors. The system works along with FaceLAB software and generates digital data in which video is recorded every $1 / 60^{\text {th }}$ of a second $(1 \mathrm{~Hz})$. Worldview software enables to see and analyze the video in a 3D format. The digital data, initially in a text file, is imported into excel for data analysis. Some features about FaceLAB include:

1. Initializing tracking automatically when face is $20 \%$ of total image,

2. Tracking and recovery up to $+/-90^{\circ},+/-45^{\circ}$ around neck axis (around head and shoulders) and vertical axis (look up or look down) respectively,

3. Tracking up to $+/-120^{\circ}$ and recovery up to $+/-30^{\circ}$ around tilt axis (lean left/right)

To avoid faulty data, the system is calibrated in relation to selected facial positions and no sun glasses are allowed.

\subsection{Participants}

The data used for this analysis was collected from drivers participating in the first part of this research. A number of participants were selected based on age and experience. Unlicensed drivers are students from University High School and Morgantown High School, whereas 
licensed drivers are mostly students, faculty and staff from West Virginia University. The terminology and detailed description of participants is as follows:

\section{i. First Group}

Thirty high school students with GDL permits (Graduated Driver Licensing), age 16 to 18 years (age average 16.4 years), and variable driving experience represent the first group of participants. These drivers are important from the GDL point of view, as this research attempts to find out the contribution of the graduate licensing program.

\section{ii. Second Group}

Thirty licensed novice drivers, age 18 to 25 years (age average 23.1), with licensed driving experience of less than one year, correspond to the second group. These novice drivers help in determining visual behavior during initial stages of licensed driving.

\section{iii. Third Group}

Thirty participants with driving experience of more than 5 years, between 30 to 50 years of age (age average 37.1), make up the group of experienced drivers. This group serves as a point of reference for normative driving.

\section{iv. First 6 months and next 6 months of licensed driving}

These drivers are taken from the second group of novice drivers with experience less than one year after getting license. These sub-groups help to calculate and compare visual behavior characteristics among novice drivers within their first 6 months ( $0-6$ months) and next 6 months (7-12 months) of license. 


\subsection{Testing Scenario}

Real-time scenario is used to determine time duration of distraction among the above mentioned groups. Initially, the eye tracking equipment (FaceLAB cameras) is placed on the dash board of a car and connected to a laptop computer in which data and video are recorded. The equipment is calibrated and adjusted for each participant to track the eye movements accurately and does not pose any additional distraction.

The first group, consisting of GDL permit holders (i.e. unlicensed high school students), drove side by side with the instructor during their driver education class along different routes depending on each participant's experience, according to the instructor's judgment. Participants were allowed and encouraged to converse with instructor; while a member of this research group was sitting in rear seat. The use of cell phone and stereo system was not permitted.

Second and third group participants drove on a familiar three-mile section of state route 705 which has 12 traffic signals, many commercial advertisement boards, and multiple driveways. To maintain similarity between the groups, participants were allowed and encouraged to converse with other passengers in the vehicle, but no cell phone or stereo systems were used either. The route chosen required making an unsignalized left turn from the buffer lane (center left-turn lane) into a parking lot by turning against oncoming traffic (Akuraju, 2009). 


\subsection{Analysis}

The data collected from FaceLAB equipment is analyzed and following eye glances are calculated to know the frequent and longer glance durations among first, second and third groups.

a) Total time duration of glances spent looking away from the roadway for more than 2 seconds per glance

b) Total time duration of glances spent looking away from the roadway for more than 2.5 seconds per glance. The 2.5 second duration is the standard perceptionreaction time recommended by AASHTO.

c) Total time duration of glances spent looking away from the roadway for more than 3 seconds per glance.

Calculated glances are divided into the three following variables. These explain the characteristics of young, novice and experienced drivers

1. Total glance duration away from roadway: This is the total time spent by driver looking away from the roadway neglecting center of road or mirrors.

2. Percentage time looking away from roadway: Percentage of time spent looking away from the roadway with respect to total driving time.

3. Number of glances away from roadway: Total number of eye glances made by driver away from the roadway.

The data collected from each participant by FaceLAB consists of multiple variables related to the eye and head movements, such as: blinking, blink duration, blink frequency, percentage closure, saccade and gaze object index, gaze object name, etc. The data is initially 
recorded in text files and then imported to spread sheets (Microsoft Excel 2007). The data is purified and simplified in such a way as to calculate the number of distractions and distraction duration.

\subsection{Data Analysis}

FaceLAB data consists of a large amount of raw information recorded every $1 / 60^{\text {th }}$ of a second, which cannot be used for analysis. Eye glances are calculated using FaceLAB created variable called "Gaze object index", which describes the direction of gaze or glances towards center, mirrors and away from them, given in numerical form as 1,2 and -1 respectively. As looking at mirrors means scanning roadway for hazards, eye glances towards center and mirrors are considered as time spent looking at roadway. So, the glances are calculated using the above criteria that time spent looking at roadway is graded as " 1 " and away from roadway is graded as “0”.

Based on criterion discussed in methodology about the glances away from roadway for more than 2 seconds, 2.5 seconds and 3 seconds, a MATLAB code is used to find out the glance duration. The code is written in such a way that duration and number of glances away from roadway are calculated. Given below are MATLAB codes for calculating glance durations 


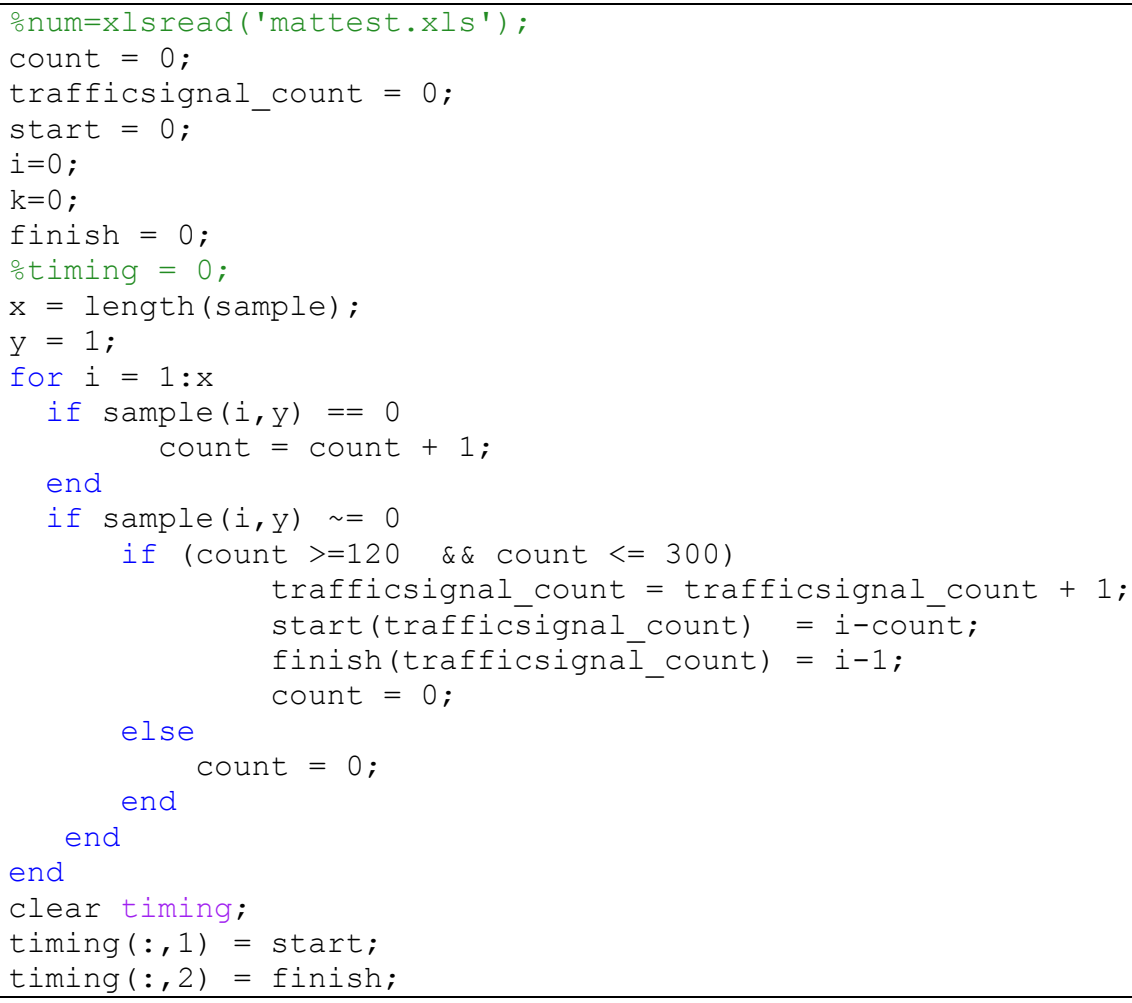

MATLAB code for Glance duration of more than 2 seconds

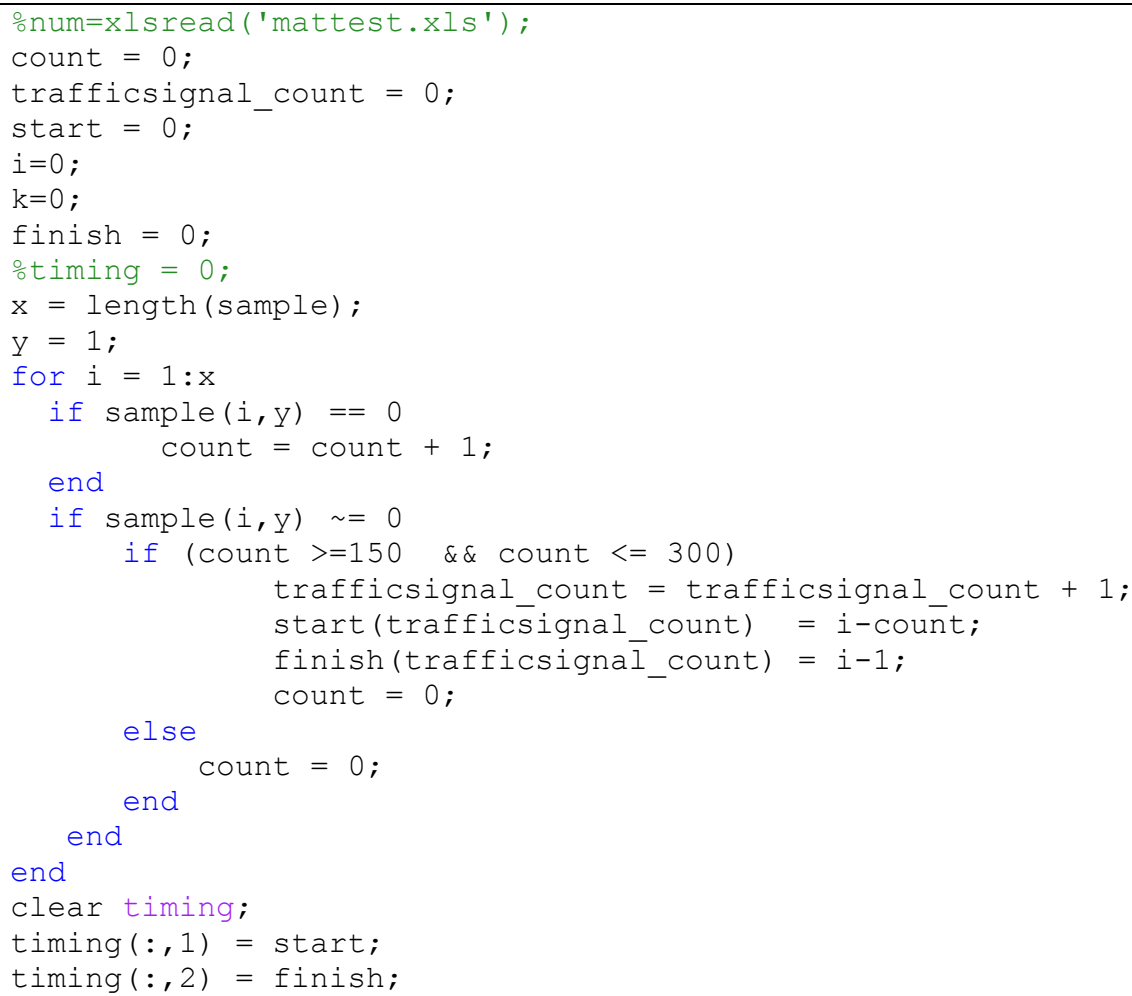

MATLAB code for Glance duration of more than 2.5 seconds 


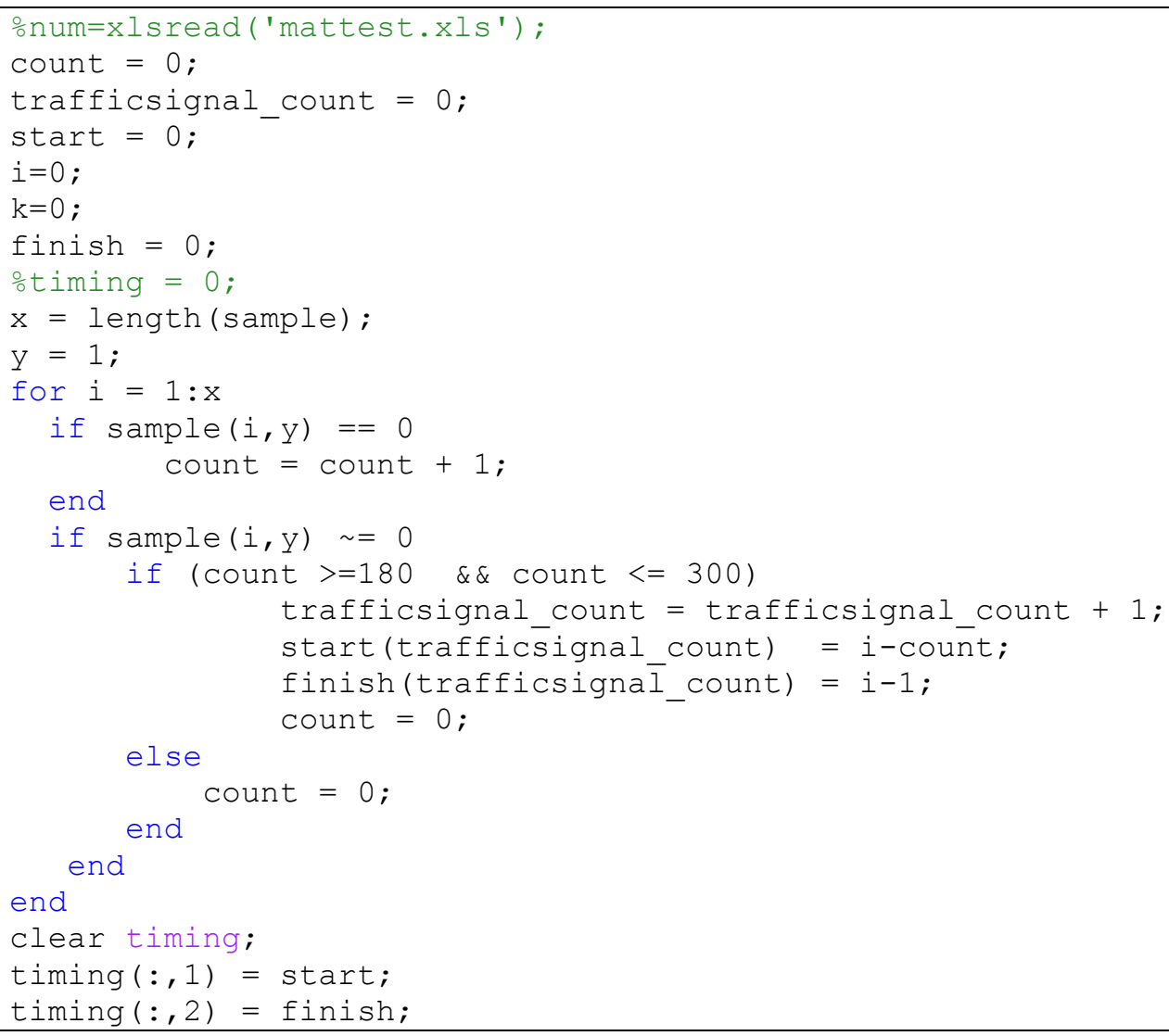

MATLAB code for Glance duration of more than 3 seconds

Statistical analysis is done to compare first, second and third groups, first 6 months with next 6 months after license among novice drivers, based on varied glance durations discussed above with the help of variables. In this way, the levels of distraction and visual behavior of drivers are analyzed in more detail and compared among different groups of drivers with varying driving experience and age. 


\section{RESULTS}

This research aims to compare distraction according to glances made away from center of road and mirrors, among young unlicensed drivers (Group 1), novice drivers (Group 2), and experienced drivers (Group 3). The values for each variable under analysis, and for each group of drivers, are statistically compared using t-test analysis. Statistical software, SAS JMP 8, is used to compare means at a confidence level of 95 percent.

The statistical software analyzes results by depicting the distribution of data, means and outliers by comparing the groups on a $\mathrm{x}-\mathrm{y}$ graph. This is followed by a t-test comparing the groups. The table below gives a glimpse of groups to compare and variables used for analysis.

\begin{tabular}{|l|}
\hline (A) Total Glance Duration away from roadway \\
(B) Percentage time looking away from roadway \\
(C) Number of Glances away from Roadway \\
(a) More than 2 sec per Glance \\
Groups: (1) Unlicensed and (3) Experienced \\
Groups: (2) Novice and (3) Experienced \\
Groups: (1) Unlicensed and (2) Novice \\
Novice Drivers: 1st Half vs. 2nd Half Year \\
More than 2.5 sec per Glance \\
Groups: (1) Unlicensed and (3) Experienced \\
Groups: (2) Novice and (3) Experienced \\
Groups: (1) Unlicensed and (2) Novice \\
Novice Drivers: 1st Half vs. 2nd Half Year \\
(b) \\
Groups: (1) Unlicensed and (3) Experienced \\
Groups: (2) Novice and (3) Experienced \\
Groups: (1) Unlicensed and (2) Novice \\
Novice Drivers: 1st Half vs. 2nd Half Year \\
(c) More than sec per Glance
\end{tabular}


Variable Used: (A) Total Glance Duration Away from Roadway Time Period Considered: (a) More than 2.0 Seconds per Glance Groups Compared: (1) Unlicensed vs. (3) Experienced Drivers

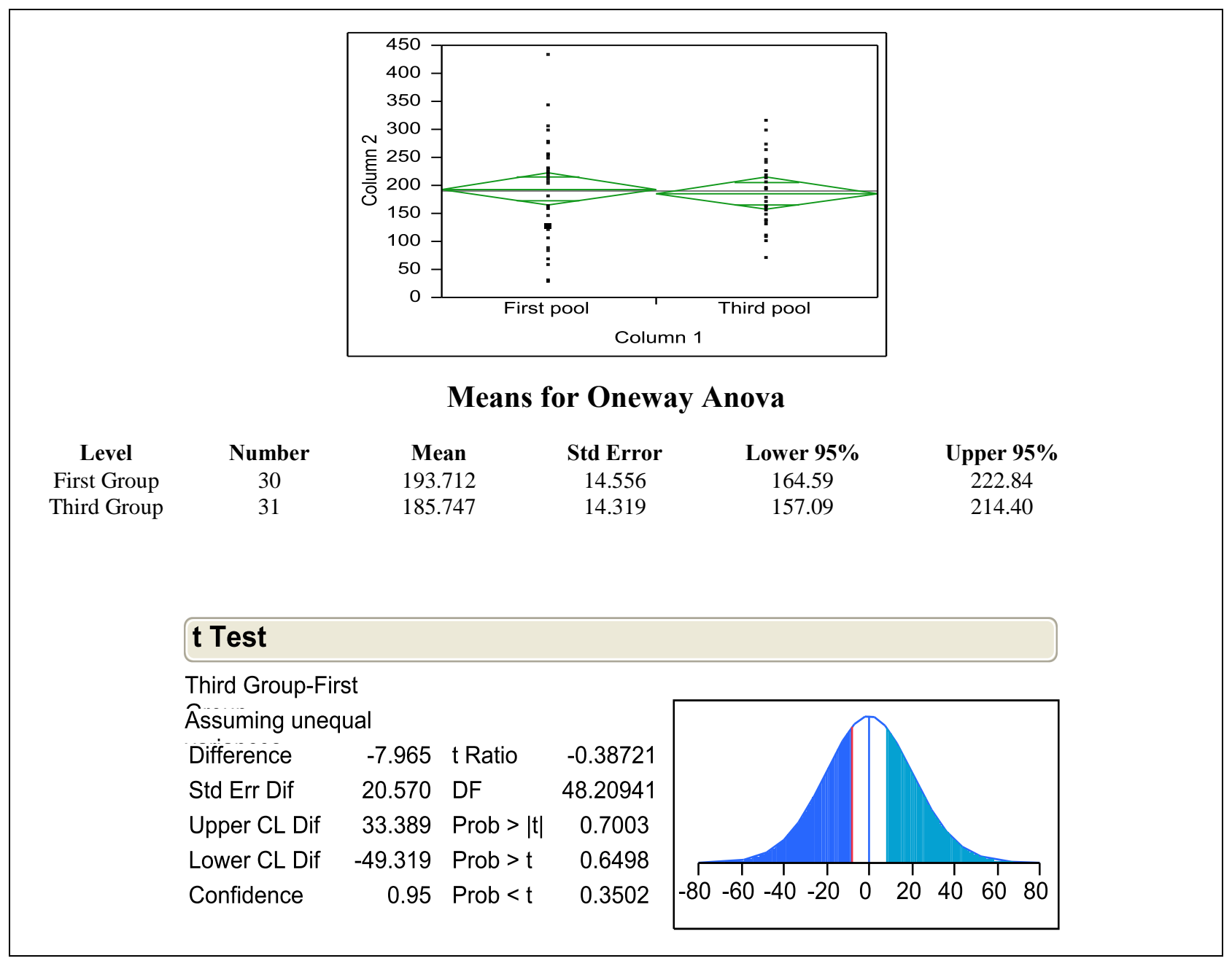

Figure 1: Total glance duration, 2 or more sec/glance, groups (1) \& (3)

In the figure above, the t-test analysis shows that the probability of difference between the means of unlicensed and experienced drivers is 0.3502 . This value does not satisfy the 95 percent significant confidence level. So, the groups are not significantly different. Therefore, no statistical difference was found between the groups 
Variable Used: (A) Total Glance Duration Away from Roadway Time Period Considered: (a) More than 2.0 Seconds per Glance Groups Compared: (2) Novice vs. (3) Experienced Drivers

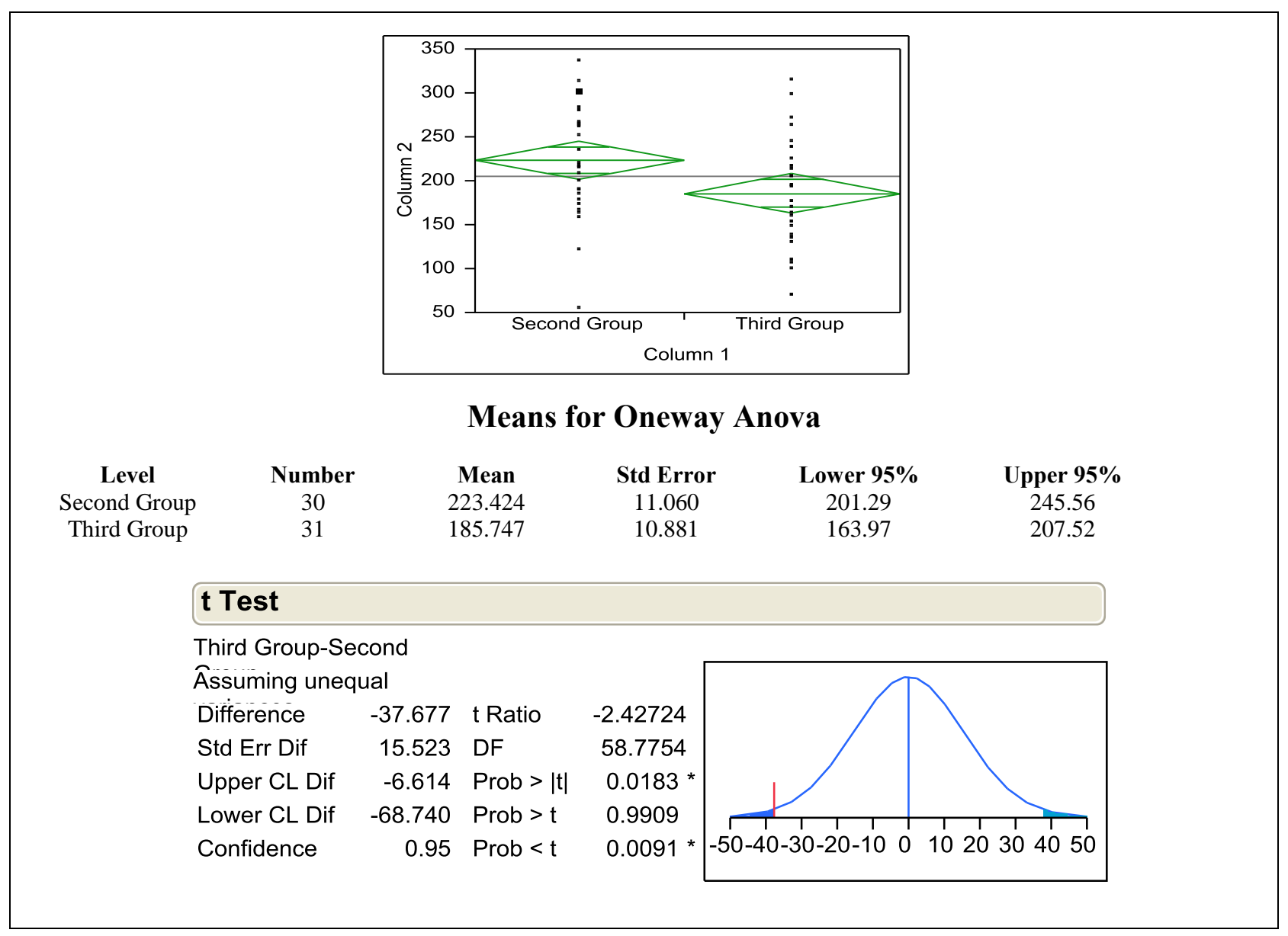

Figure 2: Total glance duration, 2 or more sec/glance, groups (2) \& (3)

In the figure above, the t-test analysis shows that the probability of difference between the means of novice and experienced drivers is $\mathbf{0 . 0 0 9 1}$ and satisfies the 95 percent confidence level. There is strong evidence that the groups are significantly different. 
Variable Used: (A) Total Glance Duration Away from Roadway Time Period Considered: (a) More than 2.0 Seconds per Glance Groups Compared: (1) Unlicensed vs. (2) Novice Drivers

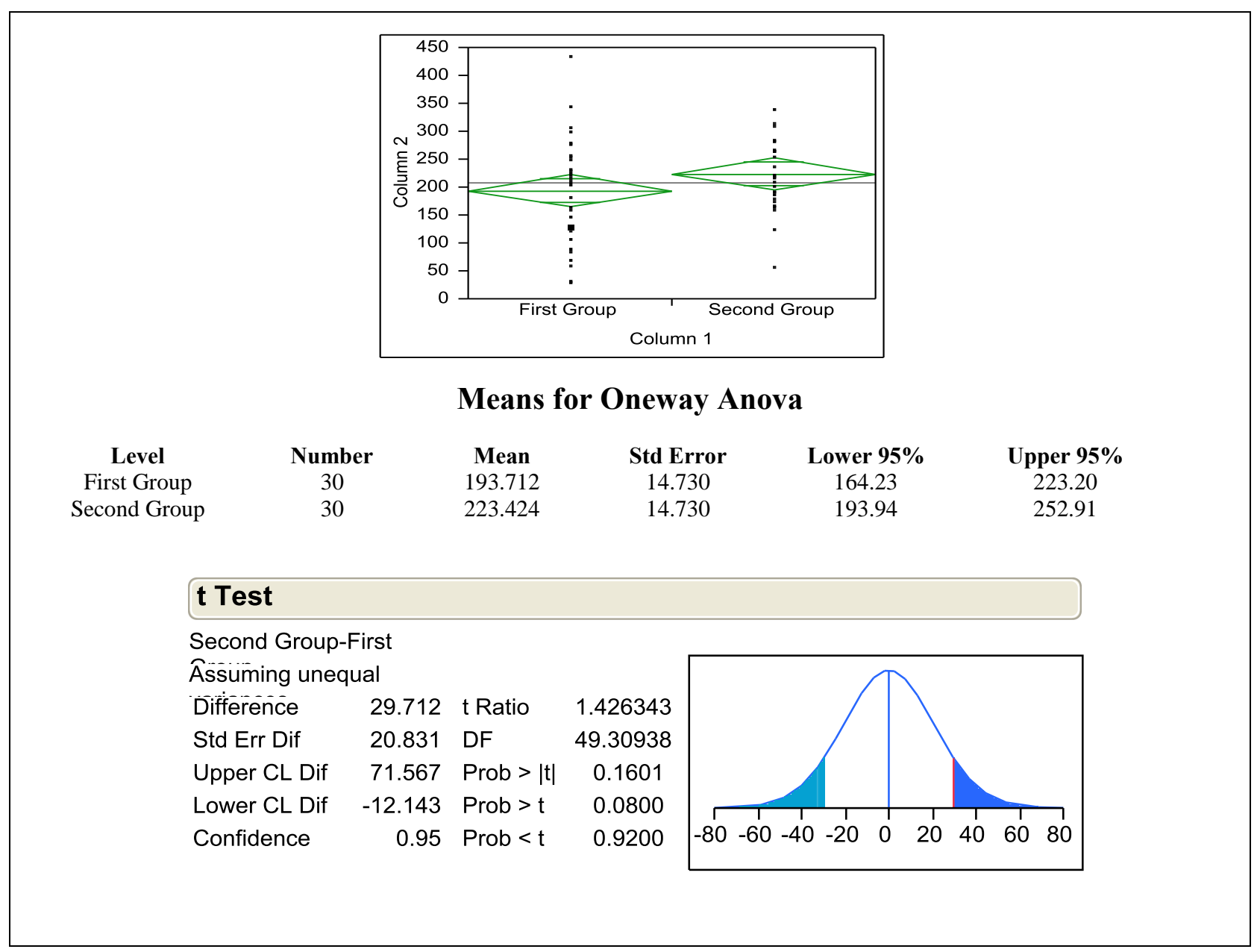

Figure 3: Total glance duration, 2 or more sec/glance, groups (1) \& (2)

In the figure above, the t-test analysis shows that the probability of difference between the means of unlicensed and a novice driver are $\mathbf{0 . 9 2 0 0}$. This value does not satisfy the 95 percent confidence level. Therefore, no statistical difference was found between the groups. 
Variable Used: (A) Total Glance Duration Away from Roadway Time Period Considered: (a) More than 2.0 Seconds per Glance

Groups Compared: Novice Drivers: First 6 months vs. Next 6 months after License

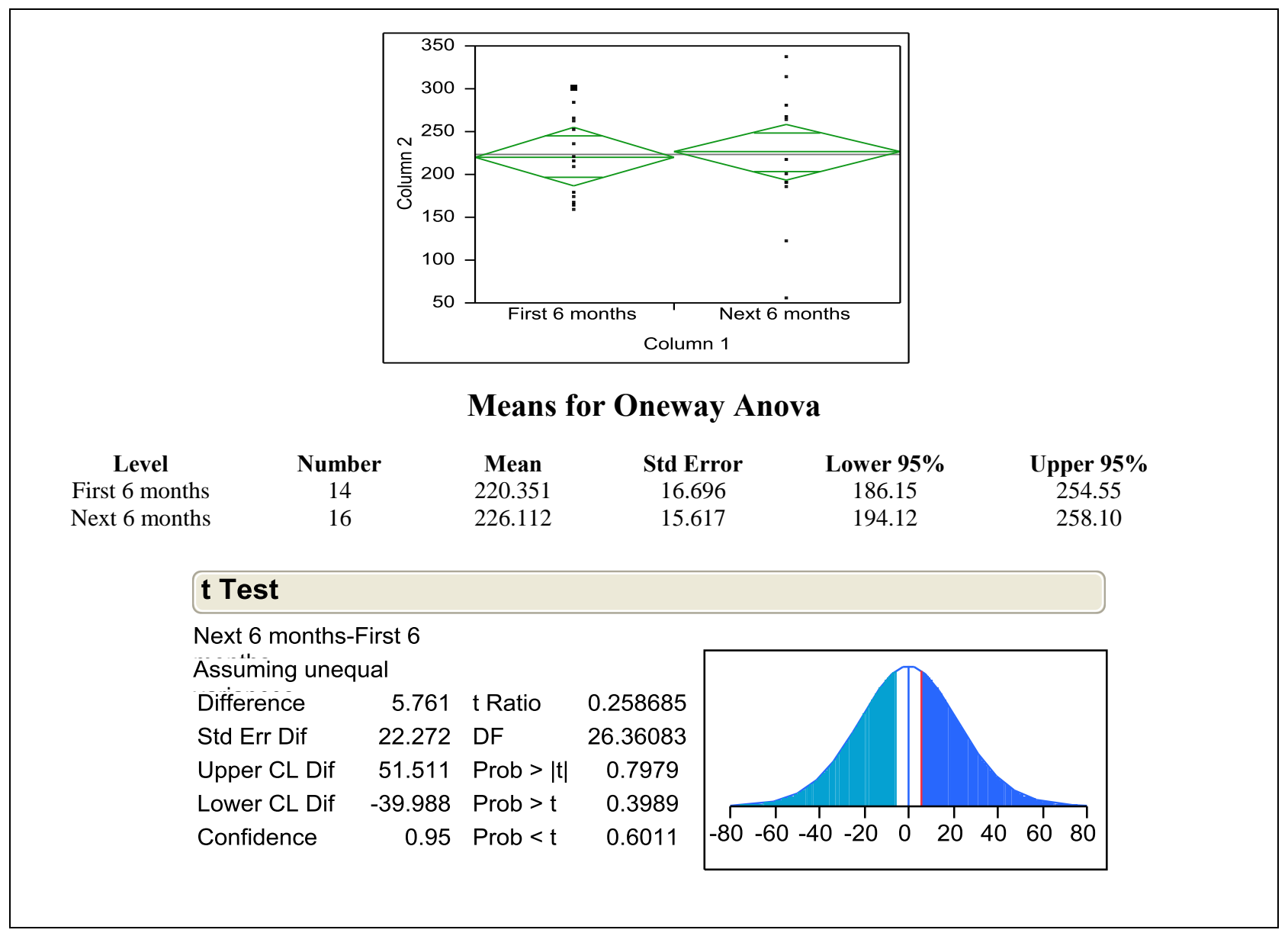

Figure 4: Total glance duration, 2 or more sec/glance, Novice drivers with first 6 months and next 6 months after license

In the figure above, the t-test analysis shows that the probability of difference between the means of novice drivers with first 6 months and next 6 months of license is $\mathbf{0 . 6 0 1 1}$. This value does not satisfy any confidence level. Therefore, no statistical difference was found between the groups. 
Variable Used: (A) Total Glance Duration Away from Roadway Time Period Considered: (b) More than 2.5 Seconds per Glance Groups Compared: (1) Unlicensed vs. (3) Experienced Drivers

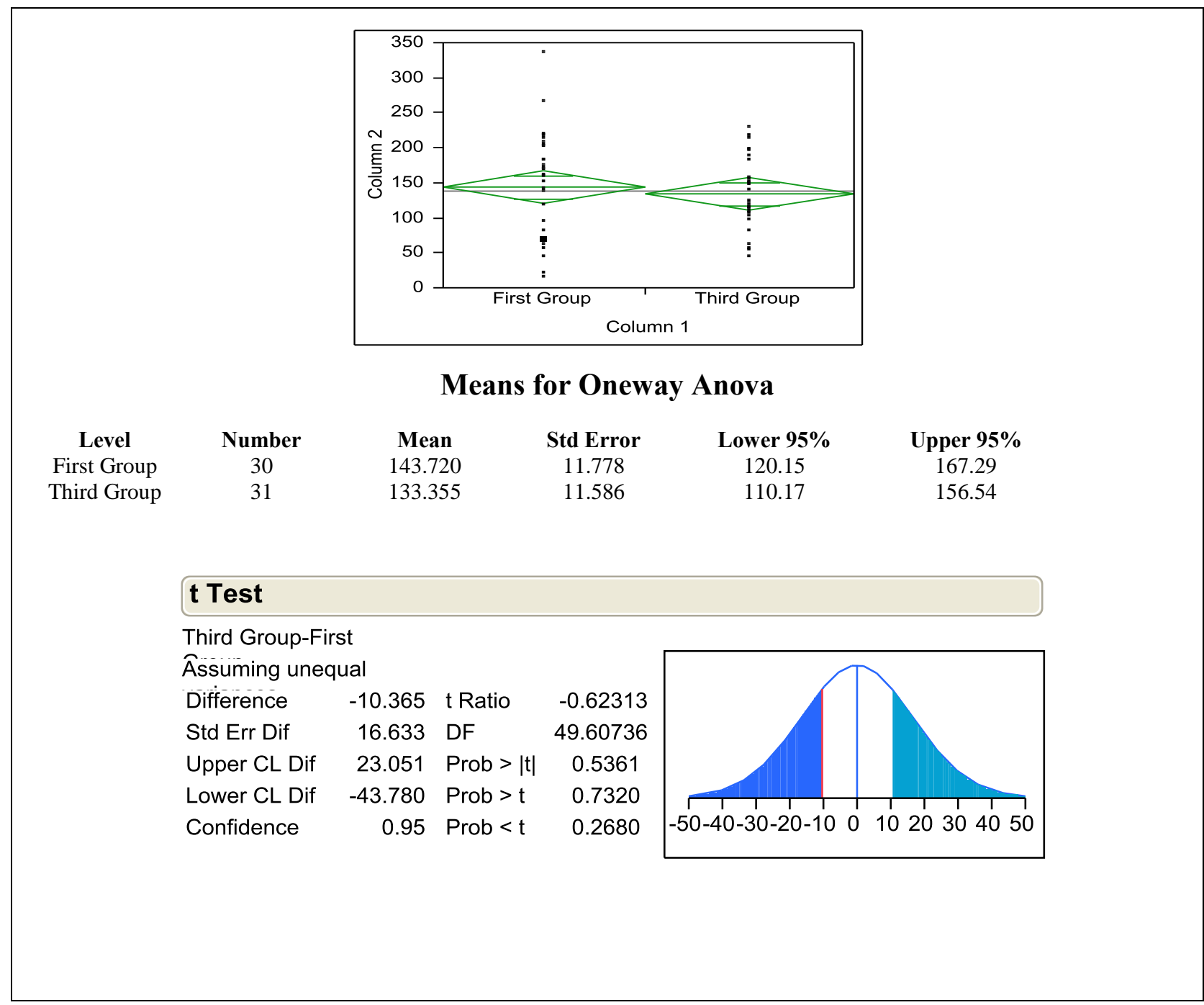

Figure 5: Total glance duration, 2.5 or more sec/glance, groups (1) \& (3)

In the figure above, the t-test analysis shows that the probability of difference between the means of unlicensed and experienced drivers is $\mathbf{0 . 2 6 8 0}$. This value does not satisfy 95 percent confidence level. Therefore, no statistical difference was found between the groups. 
Variable Used: (A) Total Glance Duration Away from Roadway Time Period Considered: (b) More than 2.5 Seconds per Glance Groups Compared: (2) Novice vs. (3) Experienced Drivers

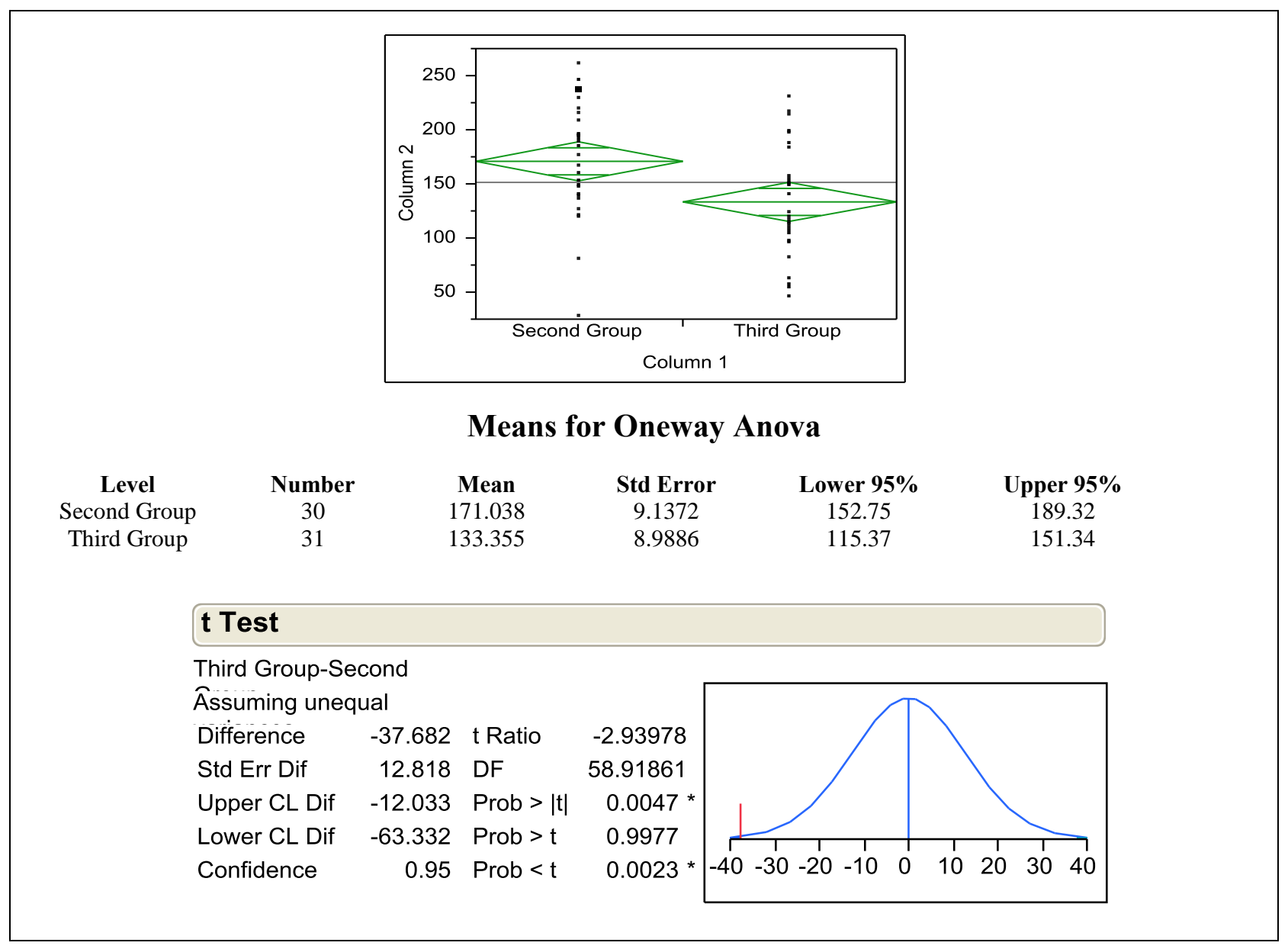

Figure 6: Total glance duration, 2.5 or more sec/glance, groups (2) \& (3)

In the figure above, the t-test analysis shows that the probability of difference between the means of novice and experienced drivers is $\mathbf{0 . 0 0 2 3}$ and ultimately satisfies the 95 percent confidence level. There is strong evidence that groups are significantly different. 
Variable Used: (A) Total Glance Duration Away from Roadway Time Period Considered: (b) More than 2.5 Seconds per Glance Groups Compared: (1) Unlicensed vs. (2) Novice Drivers

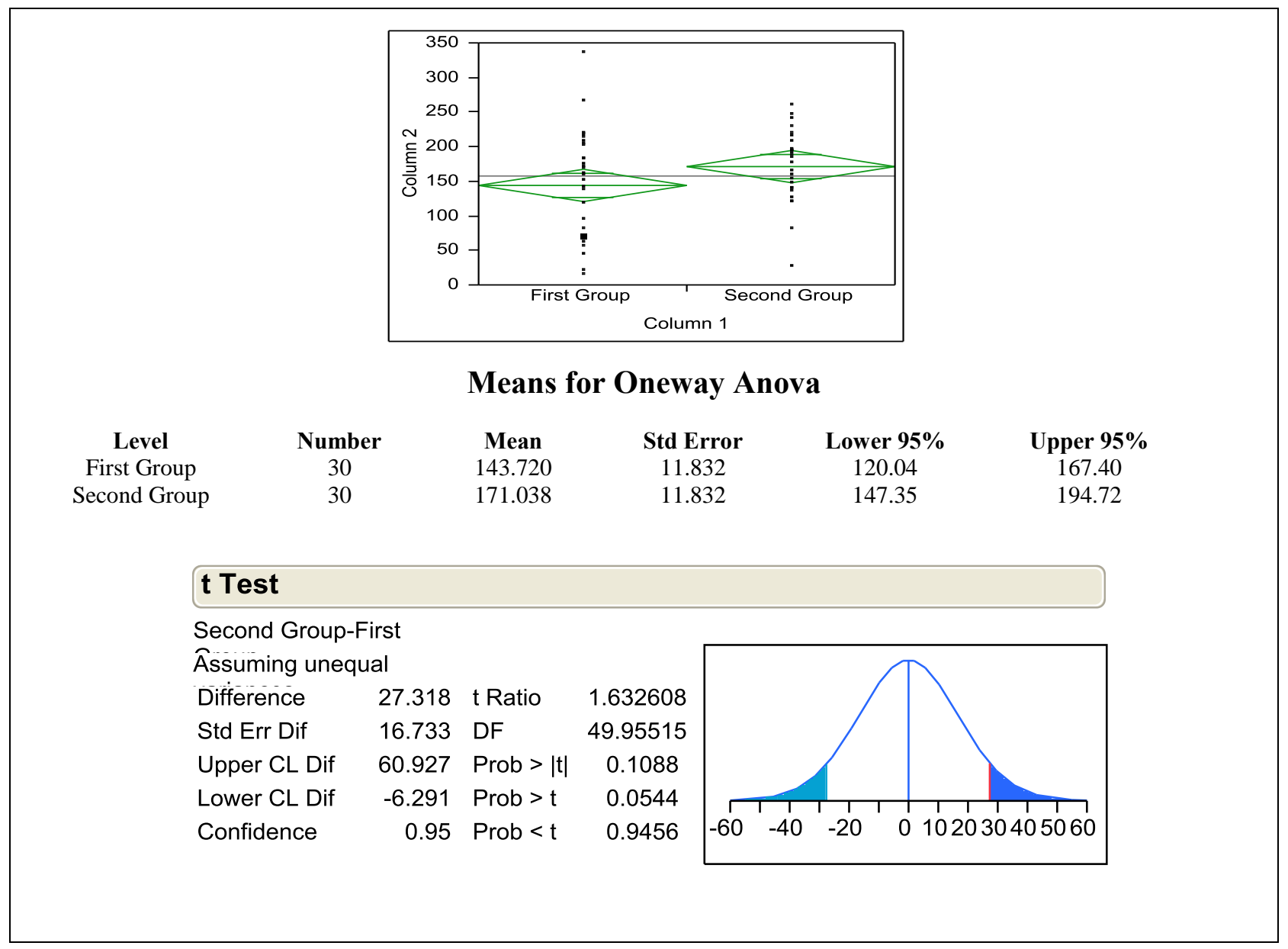

Figure 7: Total glance duration, 2.5 or more sec/glance, groups (1) \& (2)

In the figure above, the t-test analysis shows that the probability of difference between the means of unlicensed and novice drivers is $\mathbf{0 . 9 4 5 6}$. This value does not satisfy 95 percent confidence level. Therefore, no statistical difference was found between the groups. 
Variable Used: (A) Total Glance Duration Away from Roadway Time Period Considered: (a) More than 2.5 Seconds per Glance

Groups Compared: Novice Drivers: First 6 months vs. Next 6 months after License

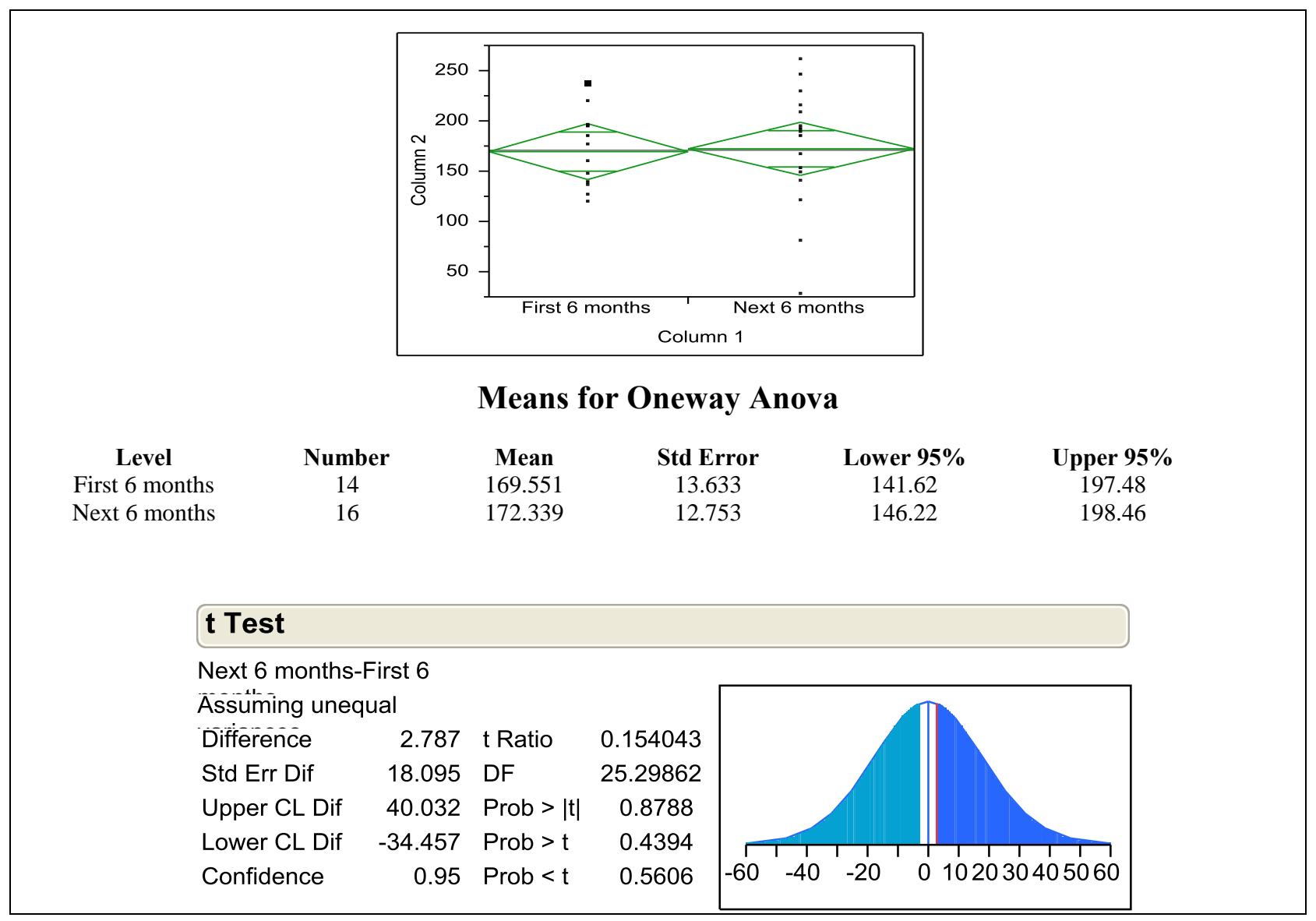

Figure 8: Total glance duration, 2.5 or more sec/glance, Novice drivers with first 6 months and next 6 months after license

In the figure above, the t-test analysis shows that the probability of difference between the means of novice drivers with first 6 months and next 6 months of license is $\mathbf{0 . 5 6 0 6}$. This value does not satisfy any confidence level. Therefore, no statistical difference was found between the groups. 
Variable Used: (A) Total Glance Duration Away from Roadway Time Period Considered: (a) More than 3 Seconds per Glance

Groups Compared: (1) Unlicensed vs. (3) Experienced Drivers

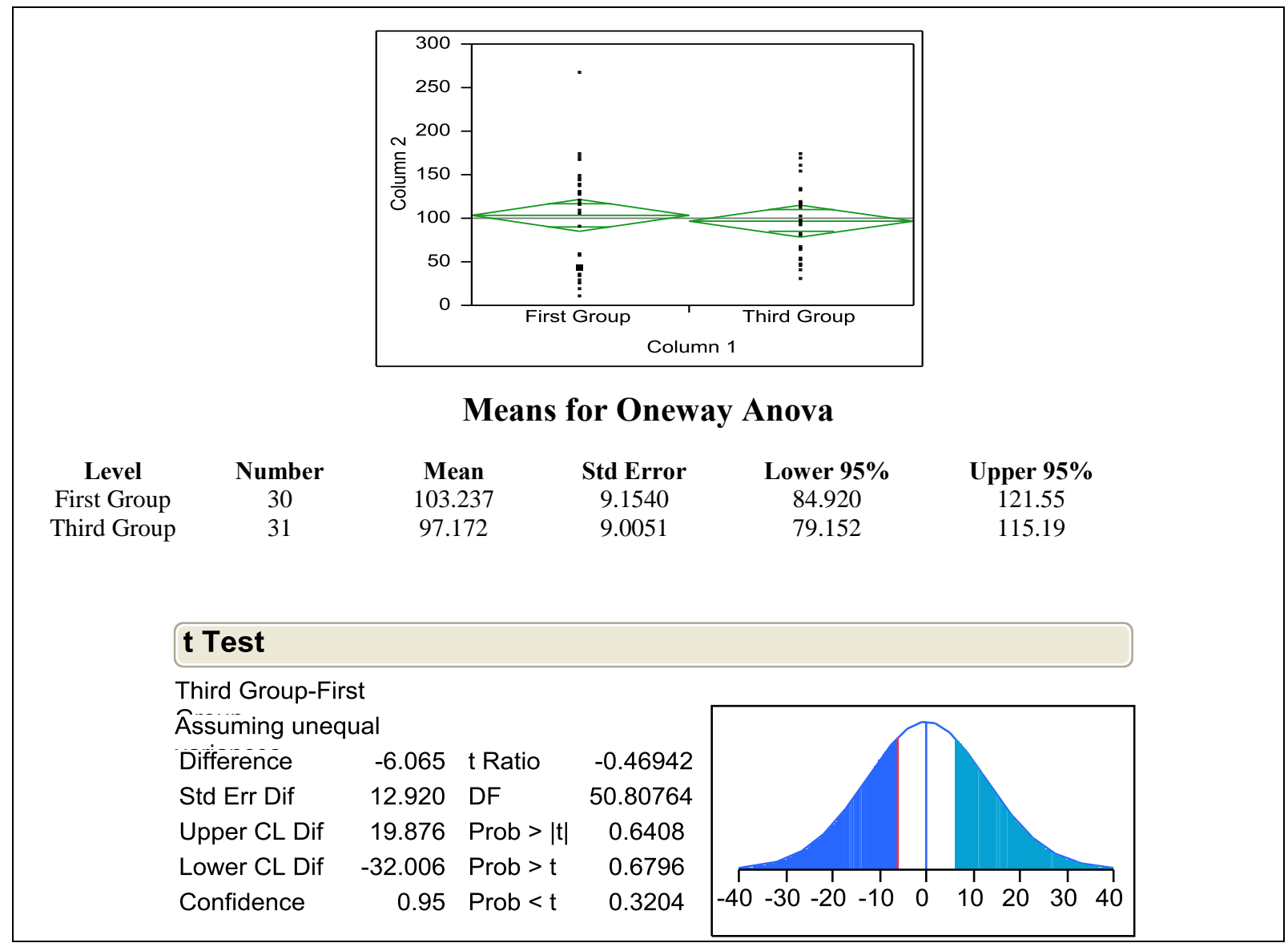

Figure 9: Total glance duration, 3 or more sec/glance, groups (1) \& (3)

In the figure above, the t-test analysis shows that the probability of difference between the means of unlicensed and experienced drivers is $\mathbf{0 . 3 2 0 4}$. This value does not satisfy 95 percent confidence level. Therefore, no statistical difference was found between the groups. 
Variable Used: (A) Total Glance Duration Away from Roadway Time Period Considered: (a) More than 3 Seconds per Glance Groups Compared: (2) Novice vs. (3) Experienced Drivers

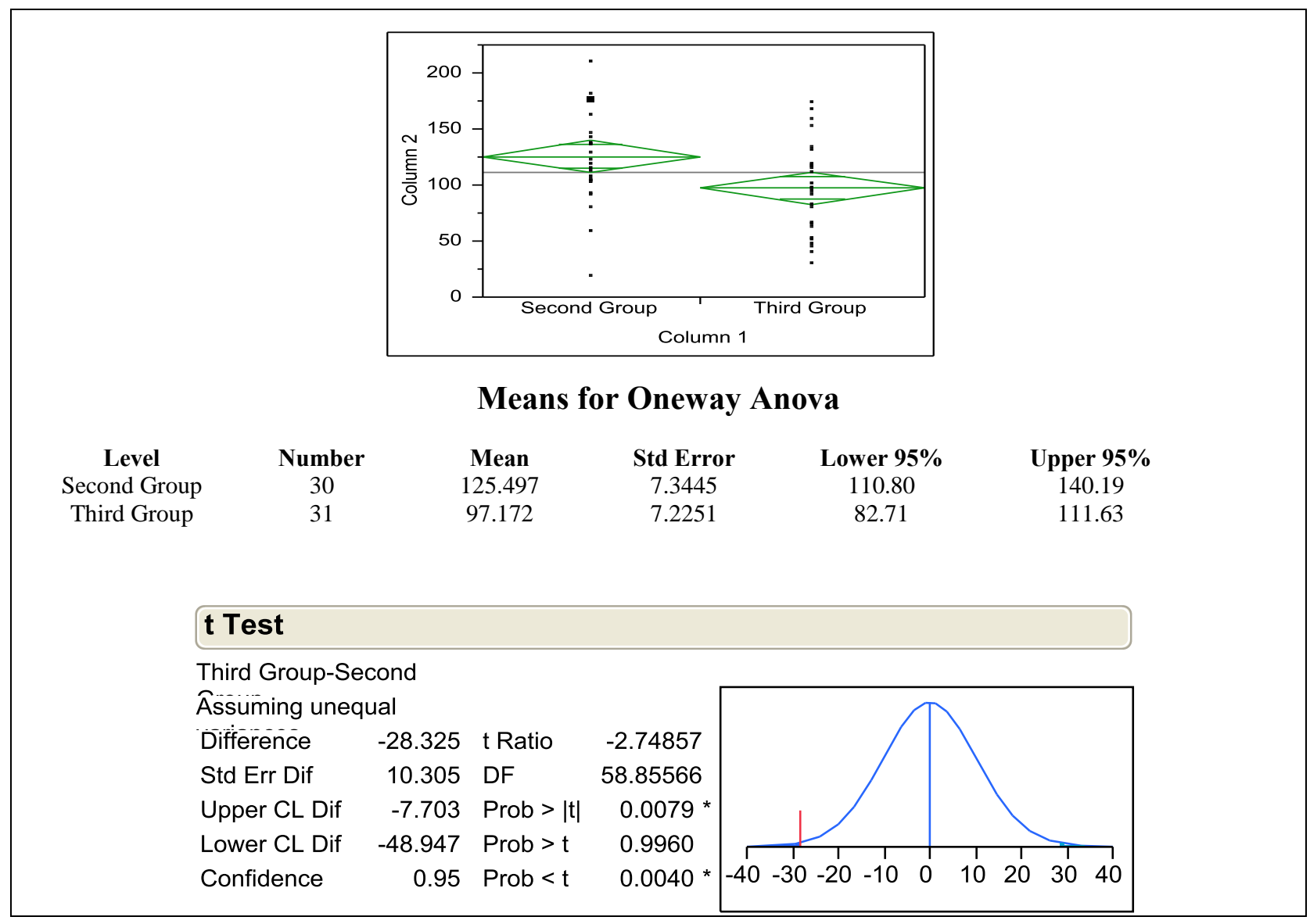

Figure 10: Total glance duration, 3 or more sec/glance, groups (2) \& (3)

In the figure above, the t-test analysis shows that the probability of difference between the means of novice and experienced drivers is $\mathbf{0 . 0 0 4 0}$ and satisfies the 95 percent confidence level. There is strong evidence that the groups are significantly different. 
Variable Used: (A) Total Glance Duration Away from Roadway Time Period Considered: (a) More than 3 Seconds per Glance Groups Compared: (1) Unlicensed vs. (2) Novice Drivers

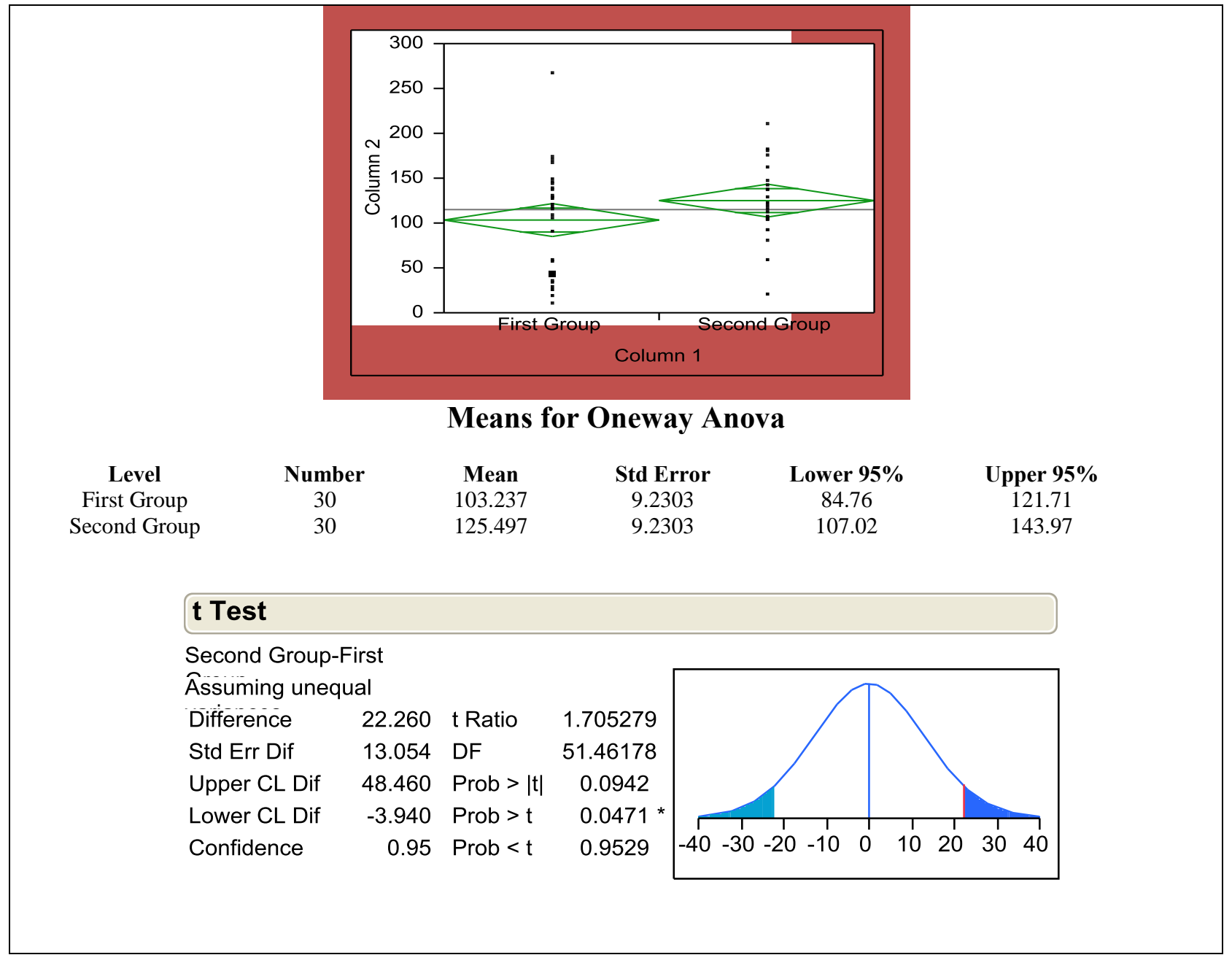

Figure 11: Total glance duration, 3 or more sec/glance, groups (1) \& (2)

In the figure above, the t-test analysis shows that the probability of difference between the means of unlicensed and novice drivers is $\mathbf{0 . 9 5 2 9}$. This value does not satisfy 95 percent confidence level. Therefore, no statistical difference was found between the groups. 
Variable Used: (A) Total Glance Duration Away from Roadway Time Period Considered: (a) More than 3 Seconds per Glance

Groups Compared: Novice Drivers: First 6 months vs. Next 6 months of License.

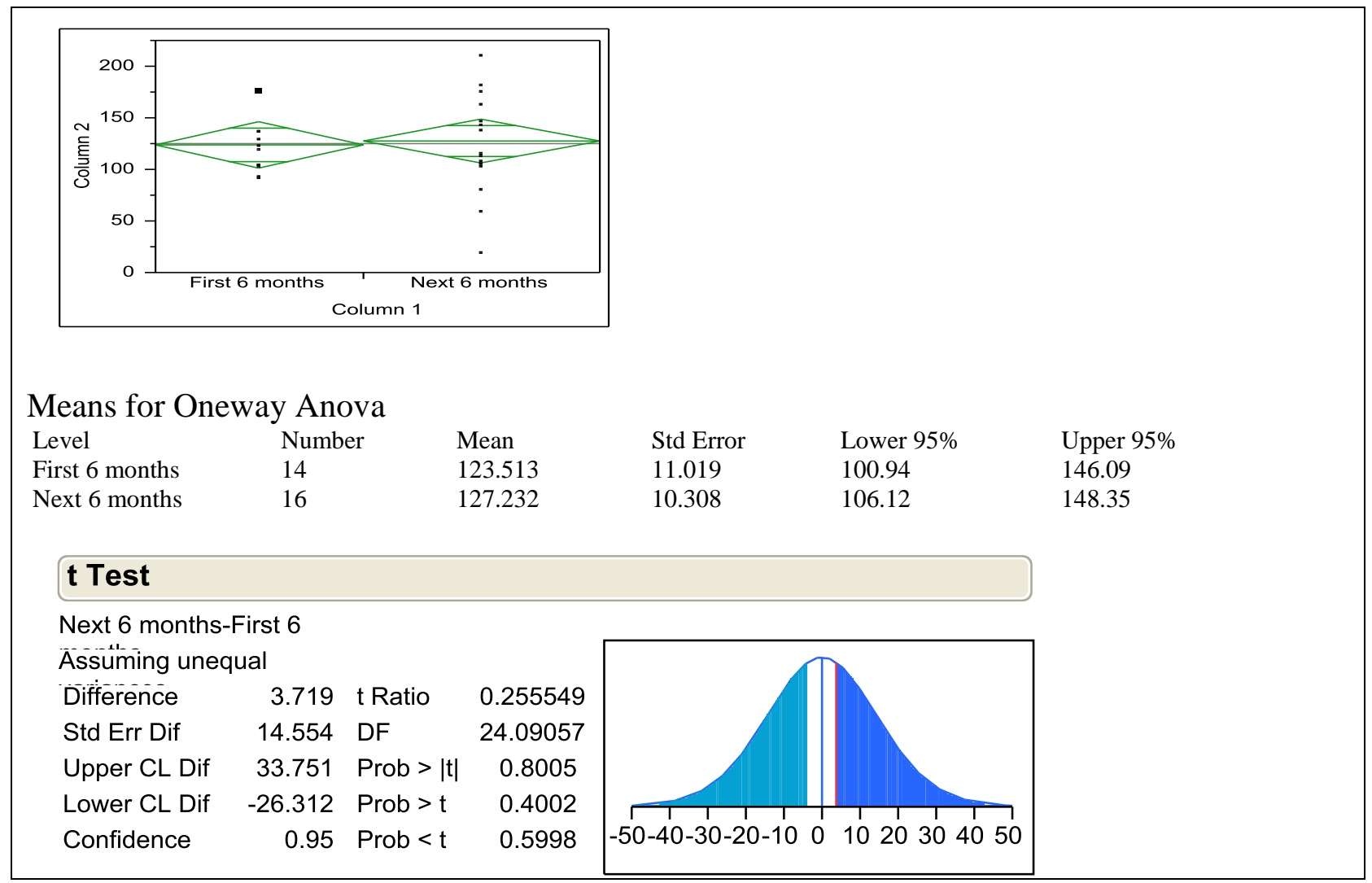

Figure 12: Total glance duration, 3 or more sec/glance, Novice drivers with first 6 months and next 6 months of license

In the figure above, the t-test analysis shows that the probability of difference between the means of novice drivers with first 6 months and next 6 months of license is $\mathbf{0 . 5 9 9 8}$. This value does not satisfy any confidence level. Therefore, no statistical difference was found between the groups. 
Variable Used: (A) Percentage time looking away from Roadway Time Period Considered: (a) More than 2.0 Seconds per Glance Groups Compared: (2) Unlicensed vs. (3) Experienced Drivers

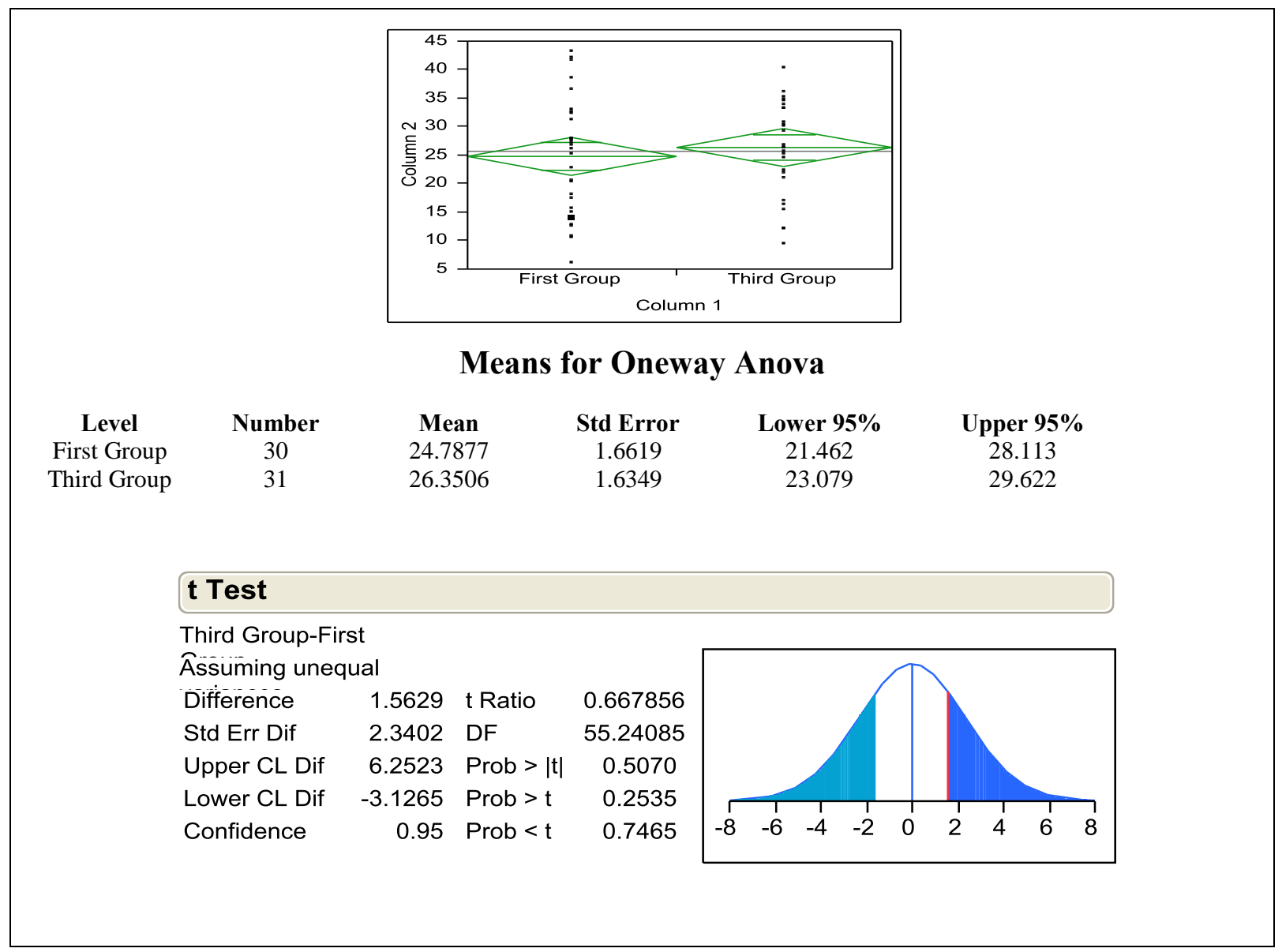

Figure 13: Percentage time looking away from roadway, 2 or more sec/glance, groups (1) \& (3)

In the figure above, the t-test analysis shows that the probability of difference between the means of unlicensed and experienced drivers is $\mathbf{0 . 7 4 6 5}$. This value does not satisfy 95 percent confidence level. Therefore, no statistical difference was found between the groups. 
Variable Used: (A) Percentage time looking away from Roadway Time Period Considered: (a) More than 2.0 Seconds per Glance

Groups Compared: (2) Novice vs. (3) Experienced Drivers

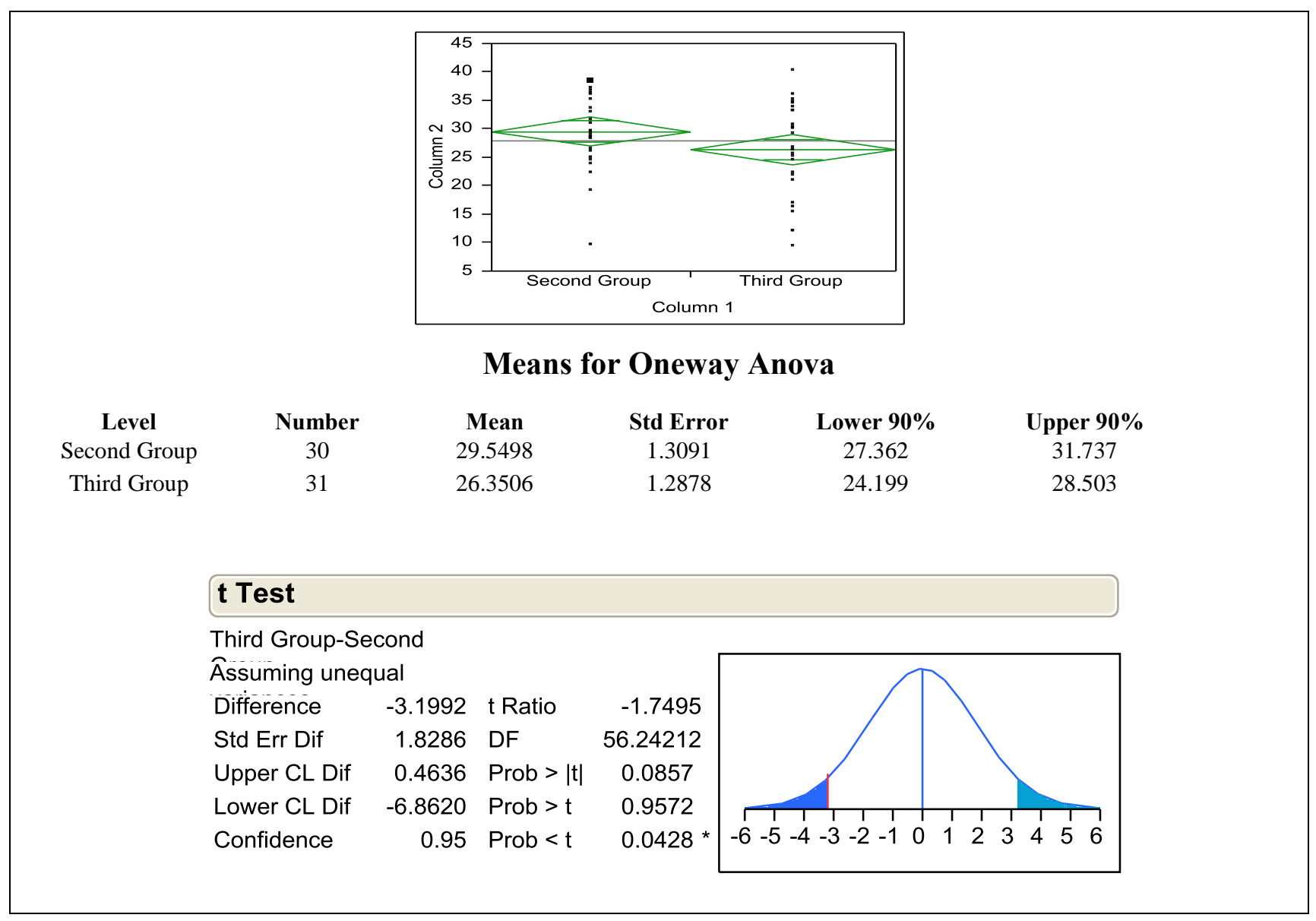

Figure 14: Percentage time looking away from roadway, 2 or more sec/glance, groups (2) \& (3)

In the figure above, the t-test analysis shows that the probability of difference between the means of novice and experienced drivers is $\mathbf{0 . 0 4 2 8}$ and satisfies the 95 percent confidence level. There is strong evidence that the groups are significantly different. 
Variable Used: (A) Percentage time looking away from Roadway Time Period Considered: (a) More than 2.0 Seconds per Glance Groups Compared: (1) Unlicensed vs. (2) Novice Drivers

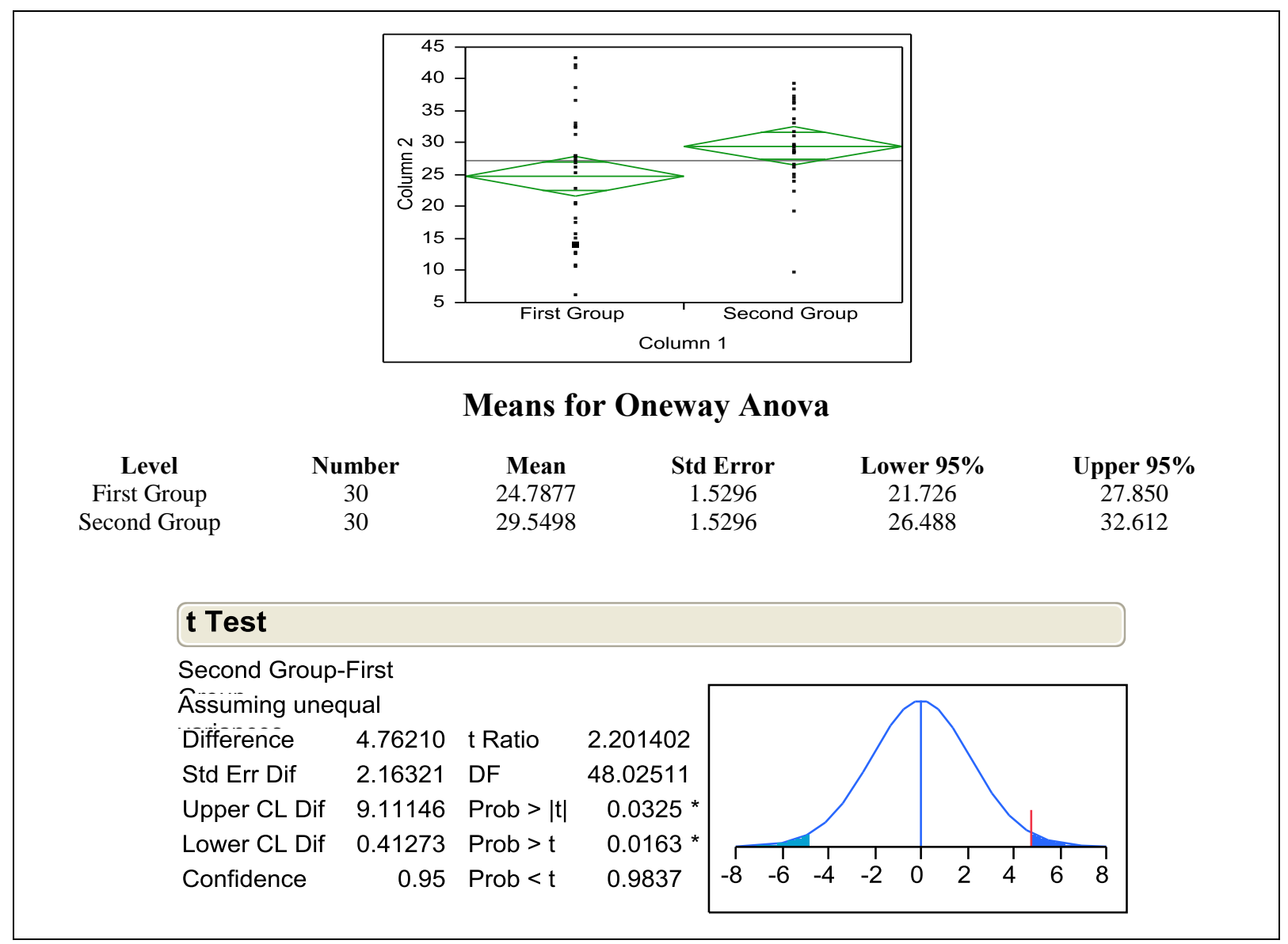

Figure 15: Percentage time looking away from roadway, 2 or more sec/glance, groups (1) \& (2)

In the figure above, the t-test analysis shows that the probability of difference between the means of unlicensed and novice drivers is $\mathbf{0 9 8 3 7}$. This value does not satisfy 95 percent confidence level. Therefore, no statistical difference was found between the groups. 
Variable Used: (A) Percentage time looking away from Roadway Time Period Considered: (a) More than 2 Seconds per Glance

Groups Compared: Novice Drivers: First 6 months vs. Next 6 months after License

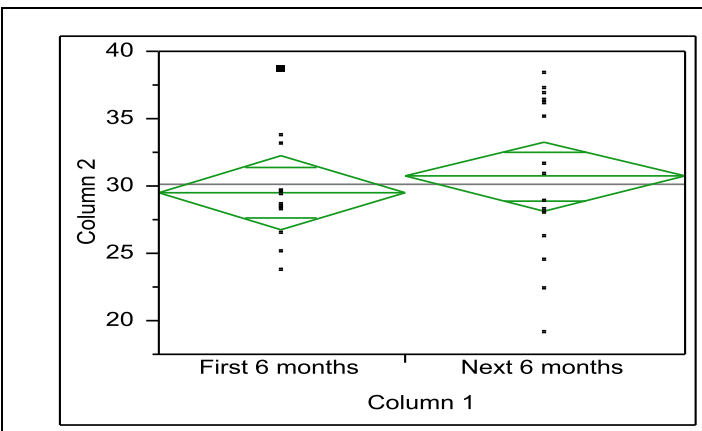

\section{Means for Oneway Anova

$\begin{array}{llllll}\text { Level } & \text { Number } & \text { Mean } & \text { Std Error } & \text { Lower 95\% } & \text { Upper 95\% } \\ \text { First 6 months } & 14 & 29.5085 & 1.3283 & 26.788 & 32.229 \\ \text { Next 6 months } & 16 & 30.7303 & 1.2425 & 28.185 & 33.275\end{array}$

\section{t Test}

Next 6 months-First 6

Assuming unequal

Difference $\quad 1.2217$ t Ratio 0.690111

Std Err Dif $\quad 1.7703$ DF 26.18437

Upper CL Dif 4.8595 Prob $>|t| \quad 0.4962$

Lower CL Dif $\quad-2.4160$ Prob $>t \quad 0.2481$

Confidence $\quad 0.95$ Prob $<\mathrm{t} \quad 0.7519$

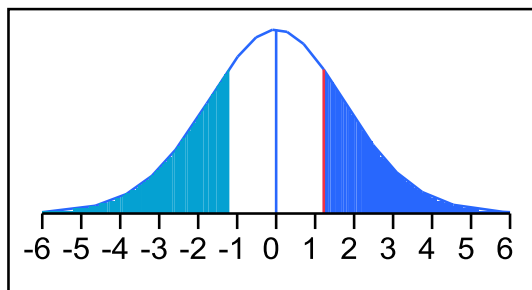

Figure 16: Percentage time looking away from roadway, 2 or more sec/glance, Novice drivers with first 6 months and next 6 months after license

In the figure above, the t-test analysis shows that the probability of difference between the means of novice drivers with first 6 months and next 6 months of license is $\mathbf{0 . 7 5 1 9}$. This value does not satisfy any confidence level. Therefore, no statistical difference was found between the groups. 
Variable Used: (A) Percentage time looking away from Roadway Time Period Considered: (a) More than 2.5 Seconds per Glance Groups Compared: (1) Unlicensed vs. (3) Experienced Drivers

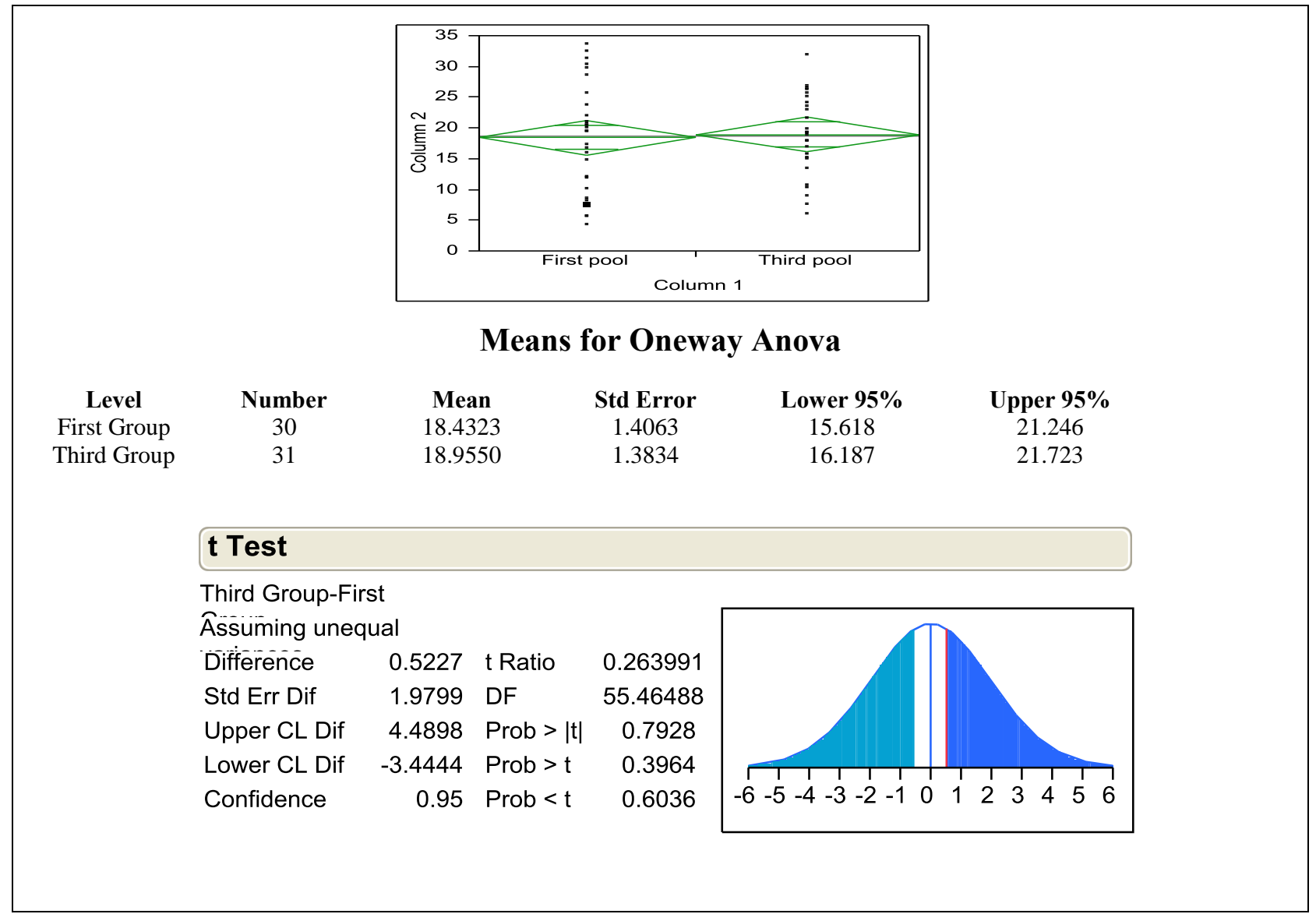

Figure 17: Percentage time looking away from roadway, 2.5 or more sec/glance, groups (1) \& (3)

In the figure above, the t-test analysis shows that the probability of difference between the means of unlicensed and experienced drivers is $\mathbf{0 . 6 0 3 6}$. This value does not satisfy 95 percent confidence level. Therefore, no statistical difference was found between the groups. 
Variable Used: (A) Percentage time looking away from Roadway Time Period Considered: (a) More than 2.5 Seconds per Glance Groups Compared: (2) Novice vs. (3) Experienced Drivers

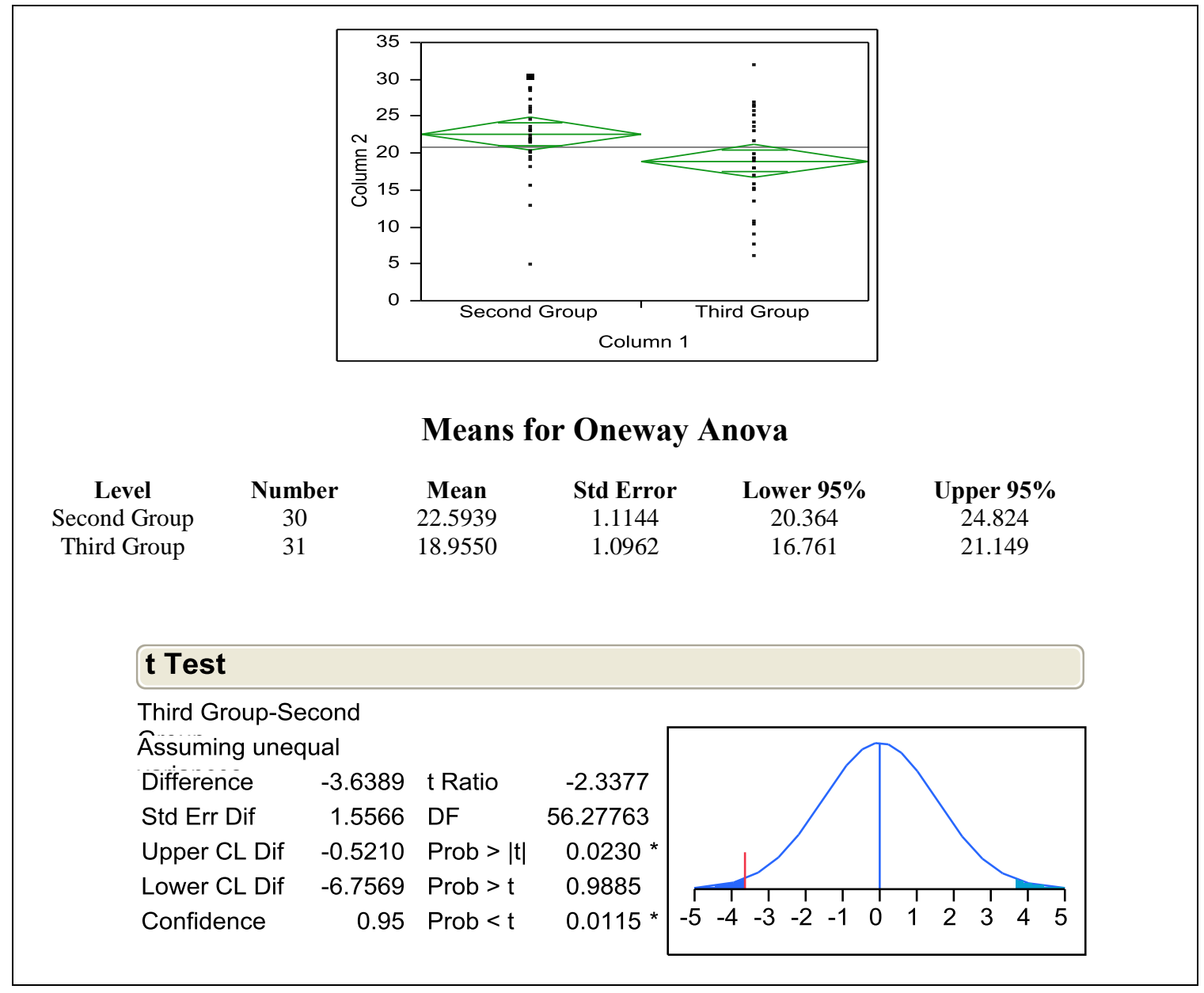

Figure 18: Percentage time looking away from roadway, 2.5 or more sec/glance, groups (2) \& (3)

In the figure above, the t-test analysis shows that the probability of difference between the means of novice and experienced drivers is $\mathbf{0 . 0 1 1 5}$ and satisfies the 95 percent confidence level. There is strong evidence that the groups are significantly different. 
Variable Used: (A) Percentage time looking away from Roadway Time Period Considered: (a) More than 2.5 Seconds per Glance Groups Compared: (2) Unlicensed vs. (3) Novice Drivers

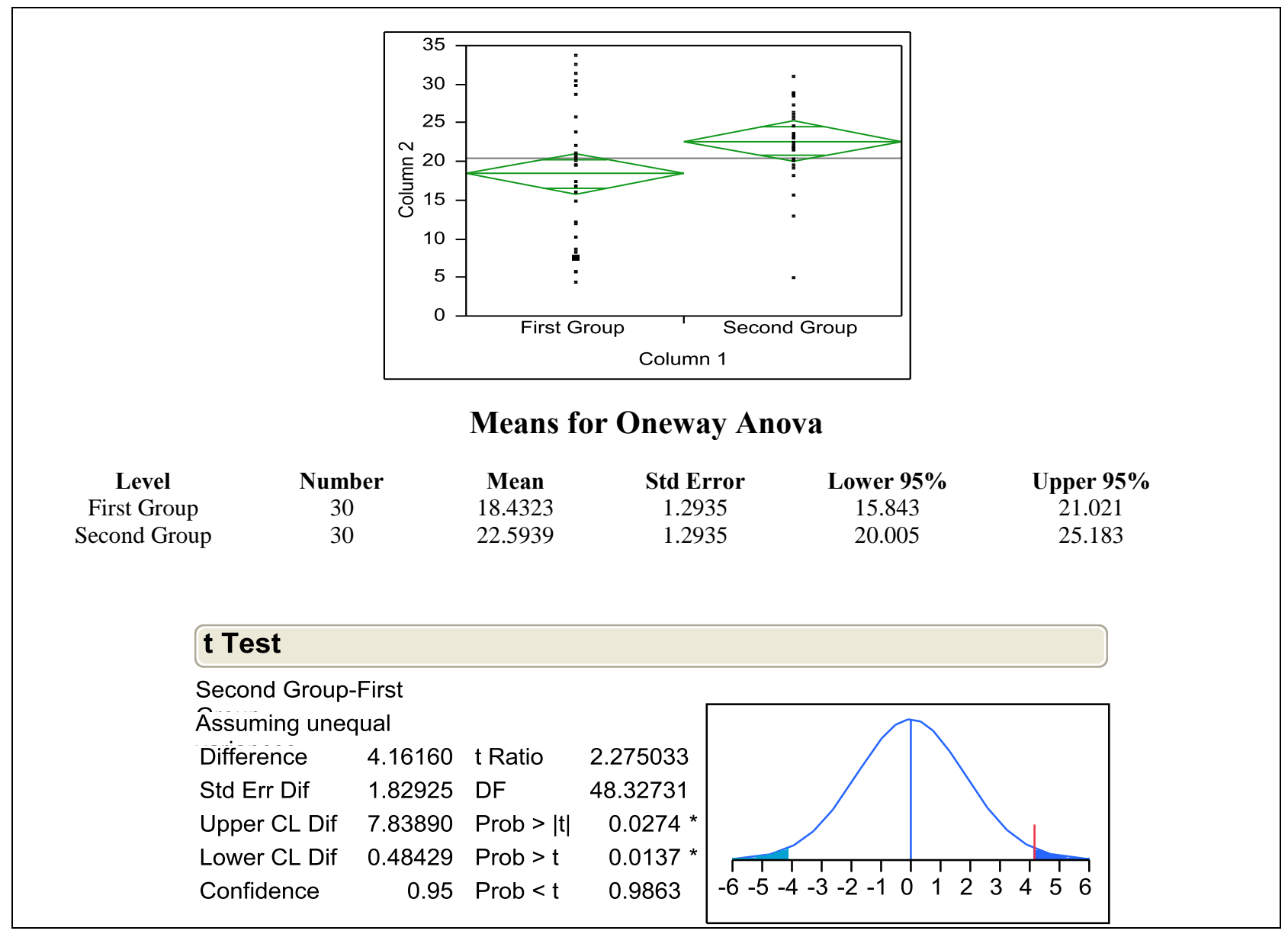

Figure 19: Percentage time looking away from roadway, 2.5 or more sec/glance, groups (1) \& (2)

In the figure above, the t-test analysis shows that the probability of difference between the means of unlicensed and novice drivers is $\mathbf{0 . 9 8 6 3}$. This value does not satisfy 95 percent confidence level. Therefore, no statistical difference was found between the groups. 
Variable Used: (A) Percentage time looking away from Roadway Time Period Considered: (a) More than 2.5 Seconds per Glance

Groups Compared: Novice Drivers: First 6 months vs. Next 6 months after License

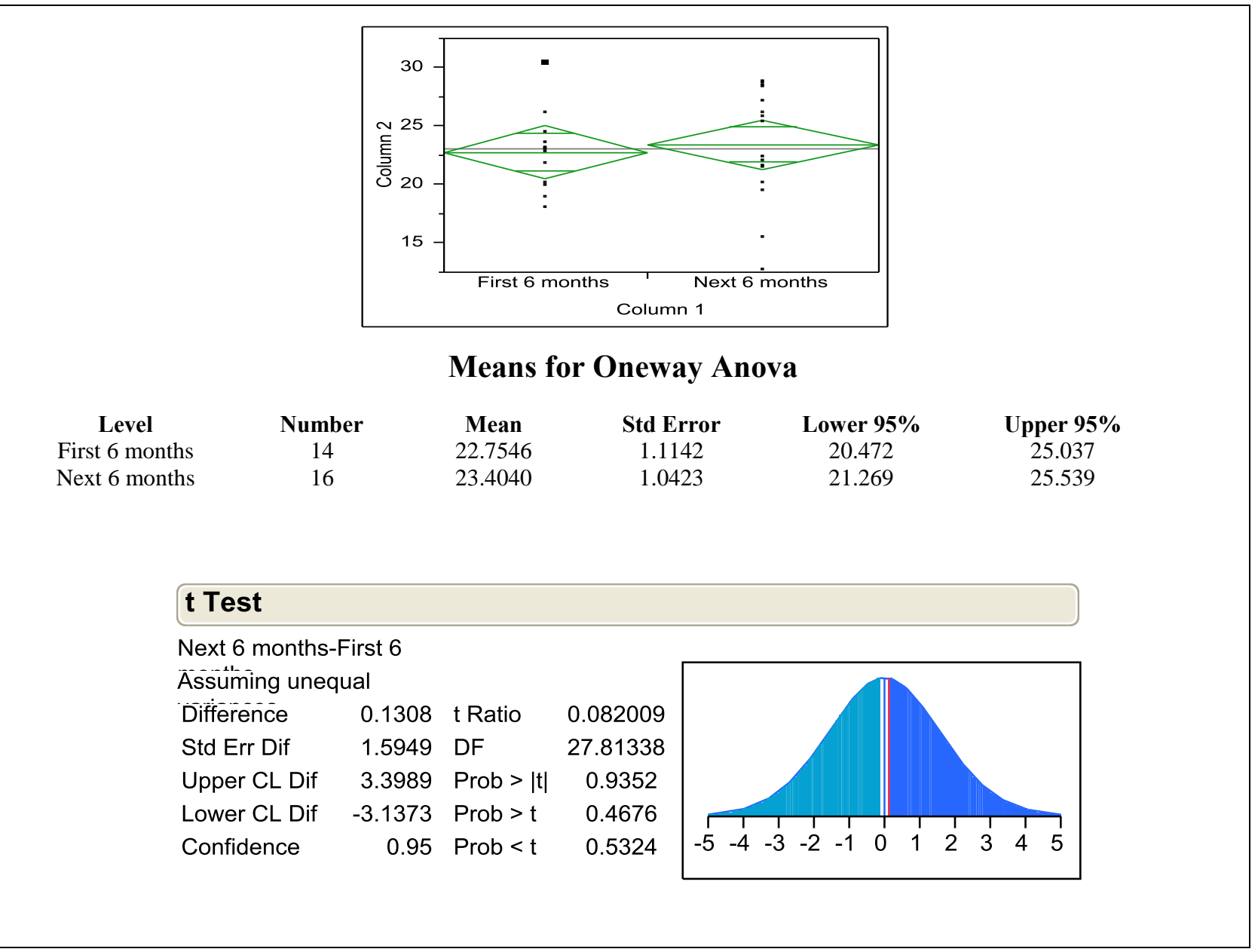

Figure 20: Percentage time looking away from roadway, 2.5 or more sec/glance, Novice drivers with first 6 months and next 6 months after license

In the figure above, the t-test analysis shows that the probability of difference between the means of novice drivers with first 6 months and next 6 months of license is $\mathbf{0 . 5 3 2 4}$. This value does not satisfy any confidence level. Therefore, no statistical difference was found between the groups. 
Variable Used: (A) Percentage time looking away from Roadway Time Period Considered: (a) More than 3 Seconds per Glance Groups Compared: (1) Unlicensed vs. (3) Experienced Drivers

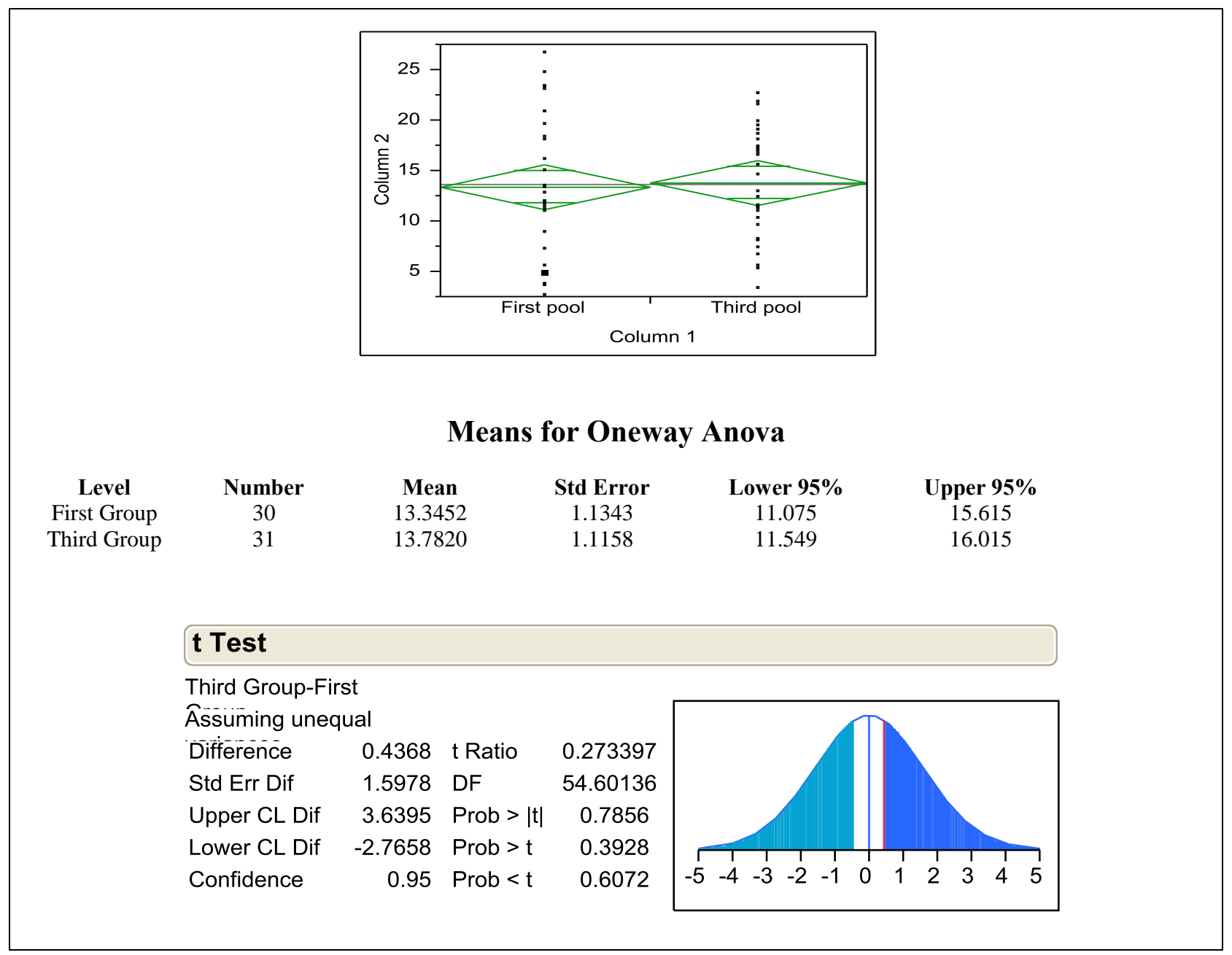

Figure 21: Percentage time looking away from roadway, 3 or more sec/glance, groups (1) \& (3)

In the figure above, the t-test analysis shows that, the probability of difference between the means of unlicensed and experienced drivers is $\mathbf{0 . 6 0 7 2}$. This value does not satisfy 95 percent confidence level. Therefore, no statistical difference was found between the groups. 
Variable Used: (A) Percentage time looking away from Roadway Time Period Considered: (a) More than 3 Seconds per Glance

Groups Compared: (2) Novice vs. (3) Experienced Drivers

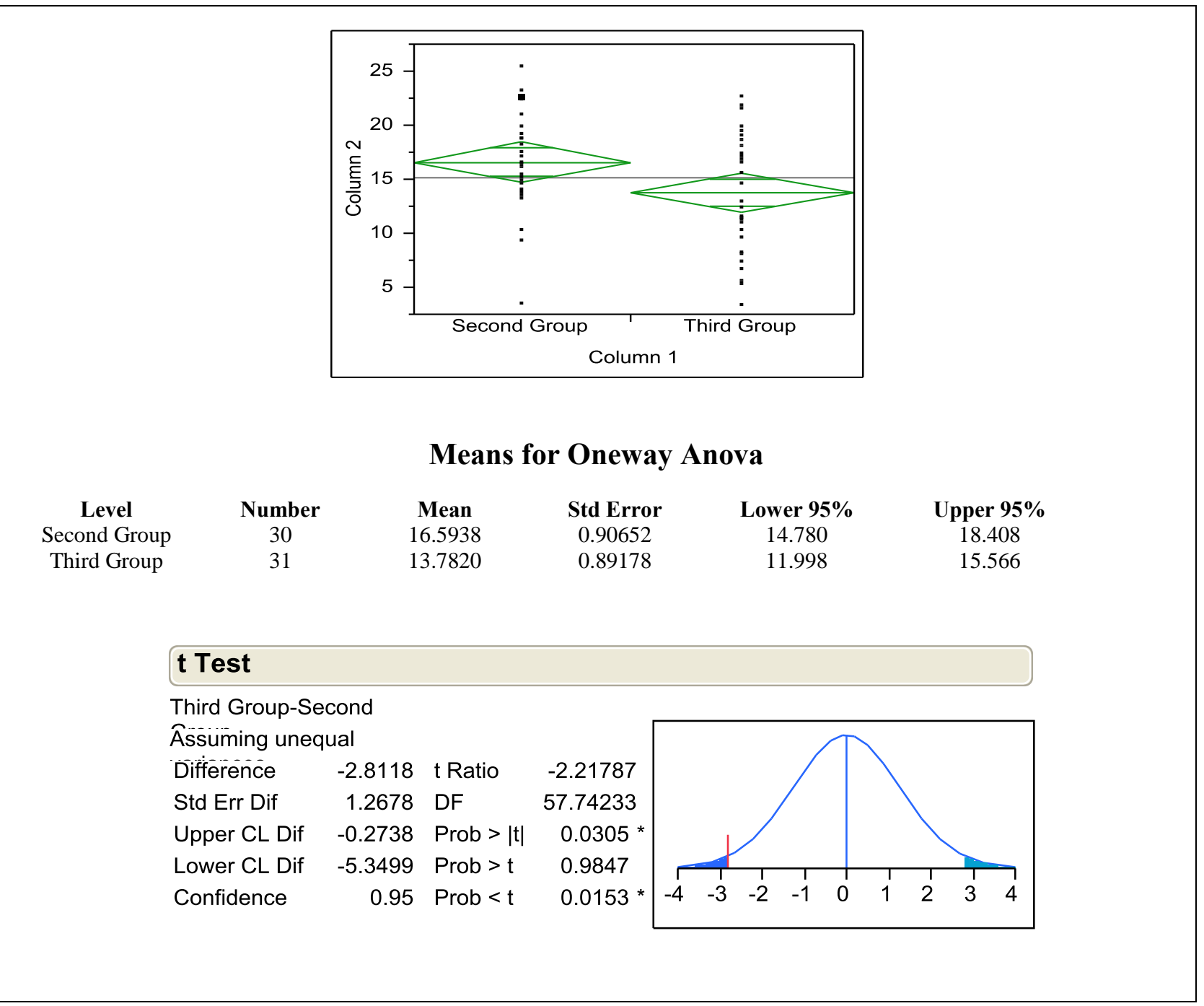

Figure 22: Percentage time looking away from roadway, 3 or more sec/glance, groups (2) \& (3)

In the figure above, the t-test analysis shows that the probability of difference between the means of novice and experienced drivers is $\mathbf{0 . 0 1 5 3}$ and satisfies the 95 percent confidence level. There is strong evidence that the groups are significantly different. 
Variable Used: (A) Percentage time looking away from Roadway Time Period Considered: (a) More than 3 Seconds per Glance

Groups Compared: (1) Unlicensed vs. (2) Novice Drivers

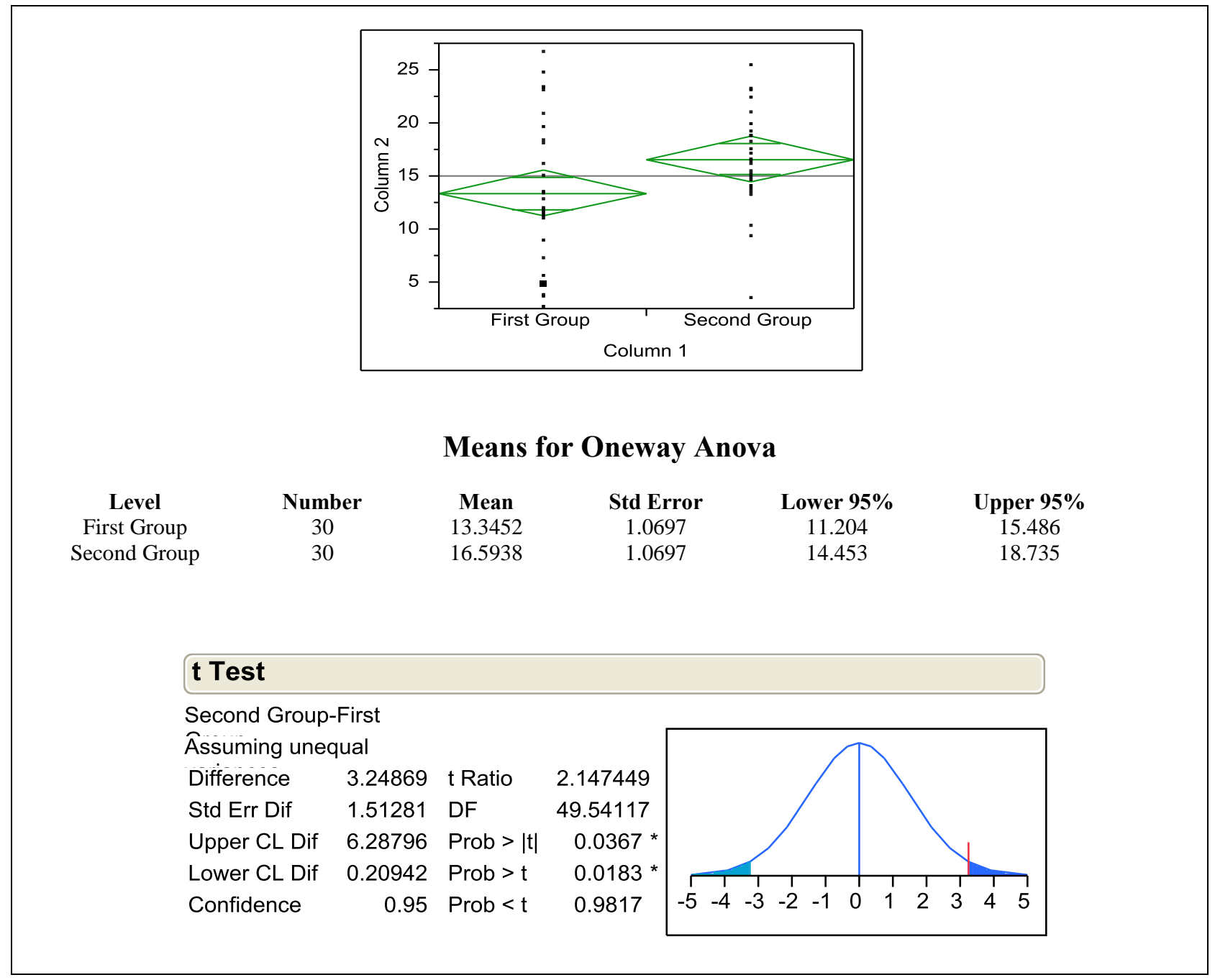

Figure 23: Percentage time looking away from roadway, 3 or more sec/glance, groups (1) \& (2)

In the figure above, the t-test analysis shows that the probability of difference between the means of unlicensed and novice drivers is $\mathbf{0 . 9 8 1 7}$. This value does not satisfy 95 percent confidence level. Therefore, no statistical difference was found between the groups. 
Variable Used: (A) Percentage time looking away from Roadway Time Period Considered: (a) More than 3 Seconds per Glance

Groups Compared: Novice Drivers: First 6 months vs. Next 6 months after License

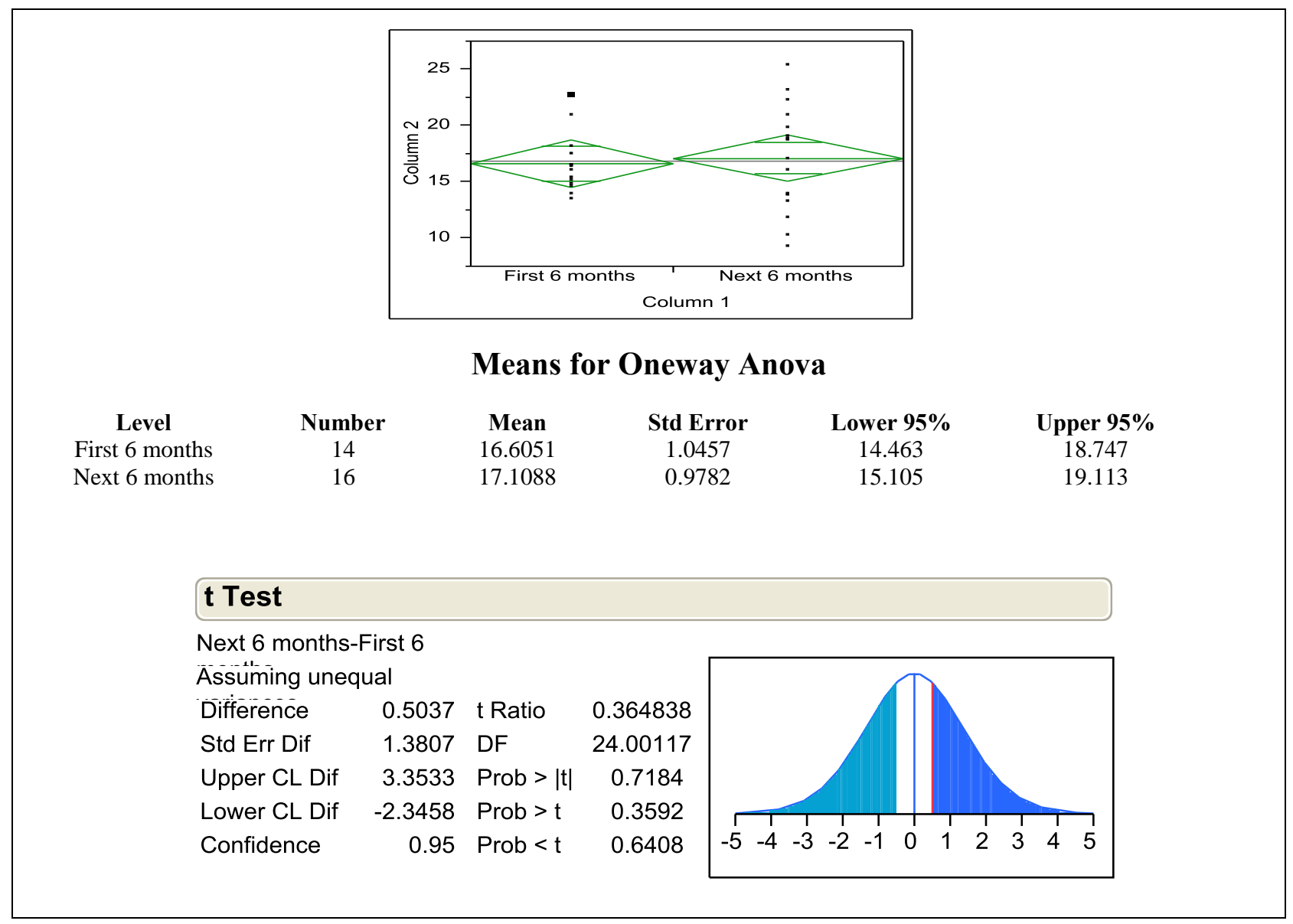

Figure 24: Percentage time looking away from roadway, 3 or more sec/glance, Novice drivers with first 6 months and next 6 months after license

In the figure above, the t-test analysis shows that the probability of difference between the means of novice drivers with first 6 months and next 6 months of license is $\mathbf{0 . 6 4 0 8}$. This value does not satisfy any confidence level. Therefore, no statistical difference was found between the groups. 
Variable Used: (A) Number of glances away from Roadway

Time Period Considered: (a) More than 2.0 Seconds per Glance

Groups Compared: (1) Unlicensed vs. (3) Experienced Drivers

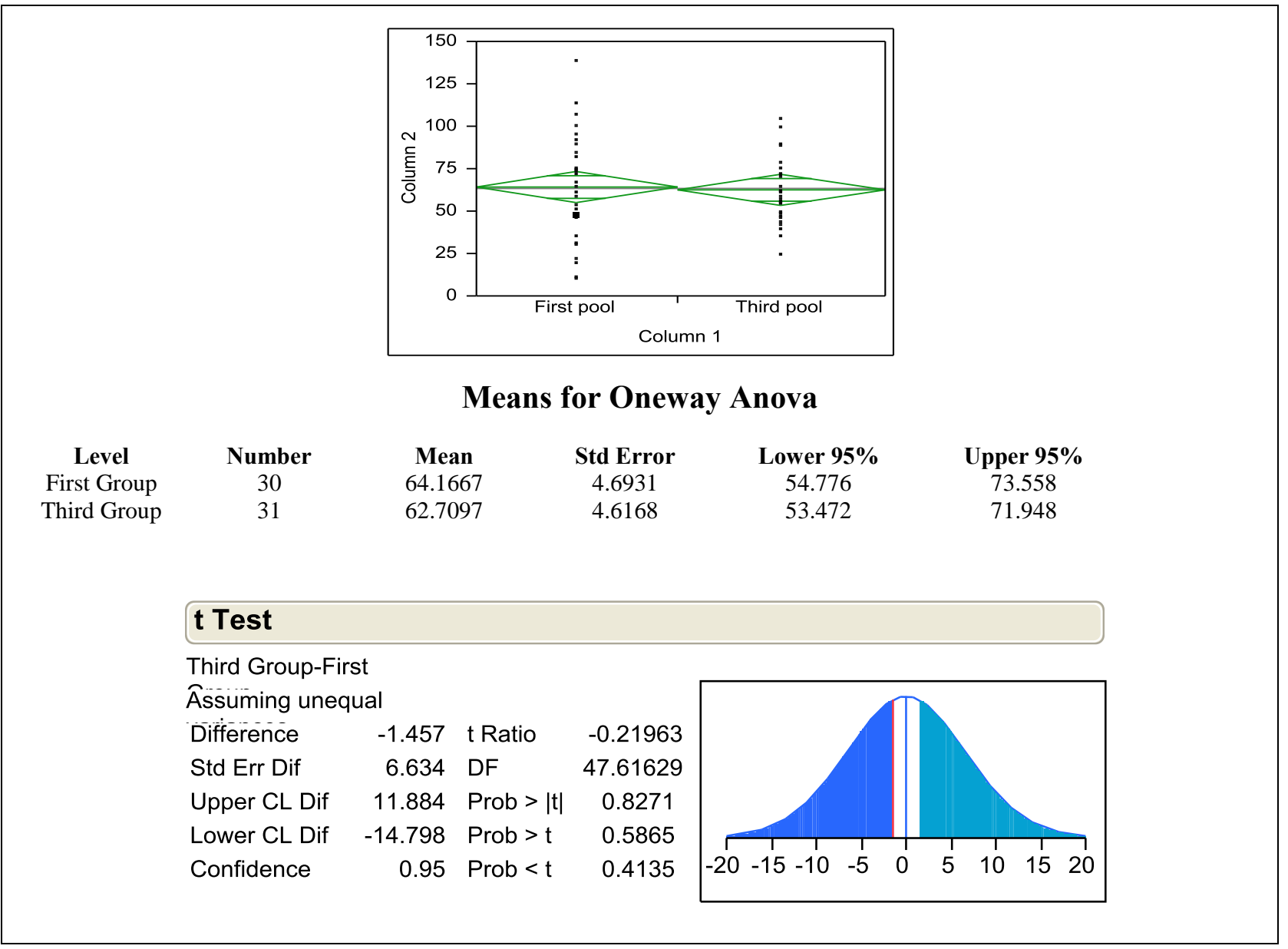

Figure 25: Number of glances away from roadway, 2 or more sec/glance, groups (1) \& (3)

In the figure above, the t-test analysis shows that the probability of difference between the means of unlicensed and experienced drivers is $\mathbf{0 . 4 1 3 5}$. This value does not satisfy 95 percent confidence level. Therefore, no statistical difference was found between the groups. 
Variable Used: (A) Number of glances away from Roadway

Time Period Considered: (a) More than 2.0 Seconds per Glance

Groups Compared: (2) Novice vs. (3) Experienced Drivers

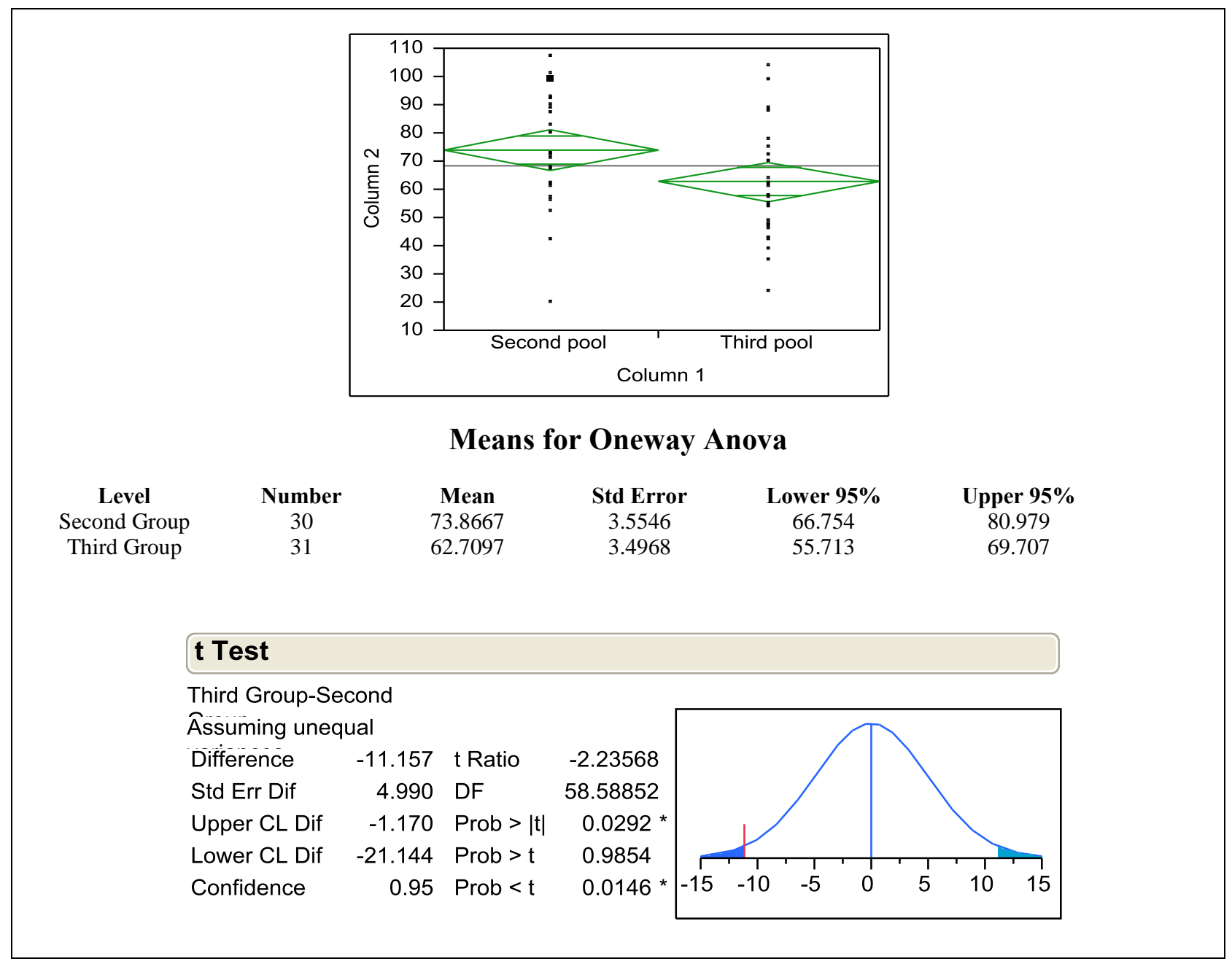

Figure 26: Number of glances away from roadway, 2 or more sec/glance, groups (2) \& (3)

In the figure above, the t-test analysis shows that the probability of difference between the means of novice and experienced drivers is $\mathbf{0 . 0 1 4 6}$ and satisfies the 95 percent confidence level. There is strong evidence that the groups are significantly different. 
Variable Used: (A) Number of glances away from Roadway

Time Period Considered: (a) More than 2.0 Seconds per Glance

Groups Compared: (1) Unlicensed vs. (3) Novice Drivers

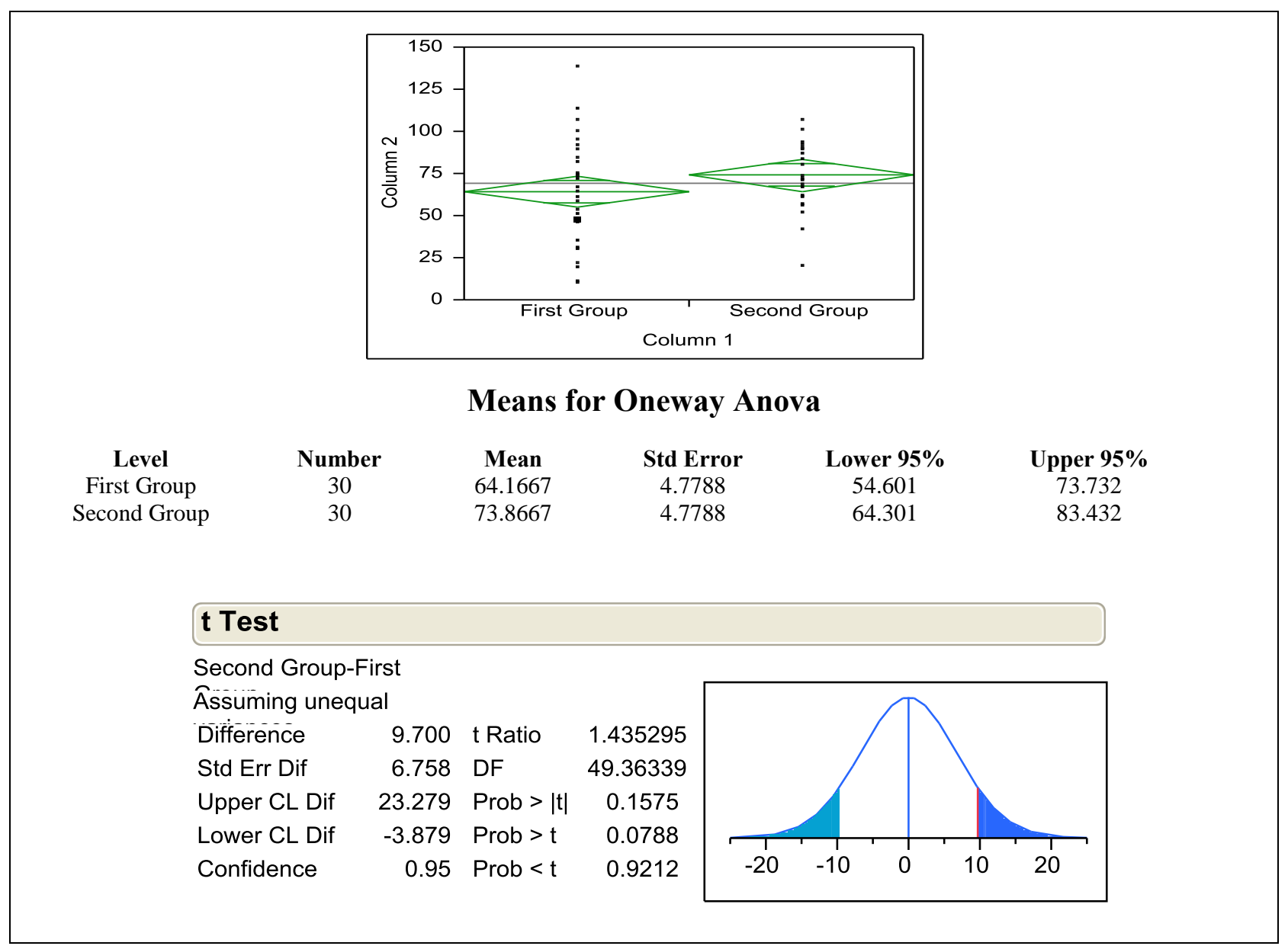

Figure 27: Number of glances away from roadway, 2 or more sec/glance, groups (1) \& (2)

In the figure above, the t-test analysis shows that the probability of difference between the means of unlicensed and novice drivers is $\mathbf{0 . 9 2 1 2}$. This value does not satisfy 95 percent confidence level. Therefore, no statistical difference was found between the groups. 
Variable Used: (A) Number of glances away from Roadway Time Period Considered: (a) More than 2.0 Seconds per Glance

Groups Compared: Novice Drivers: First 6 months vs. Next 6 months after License

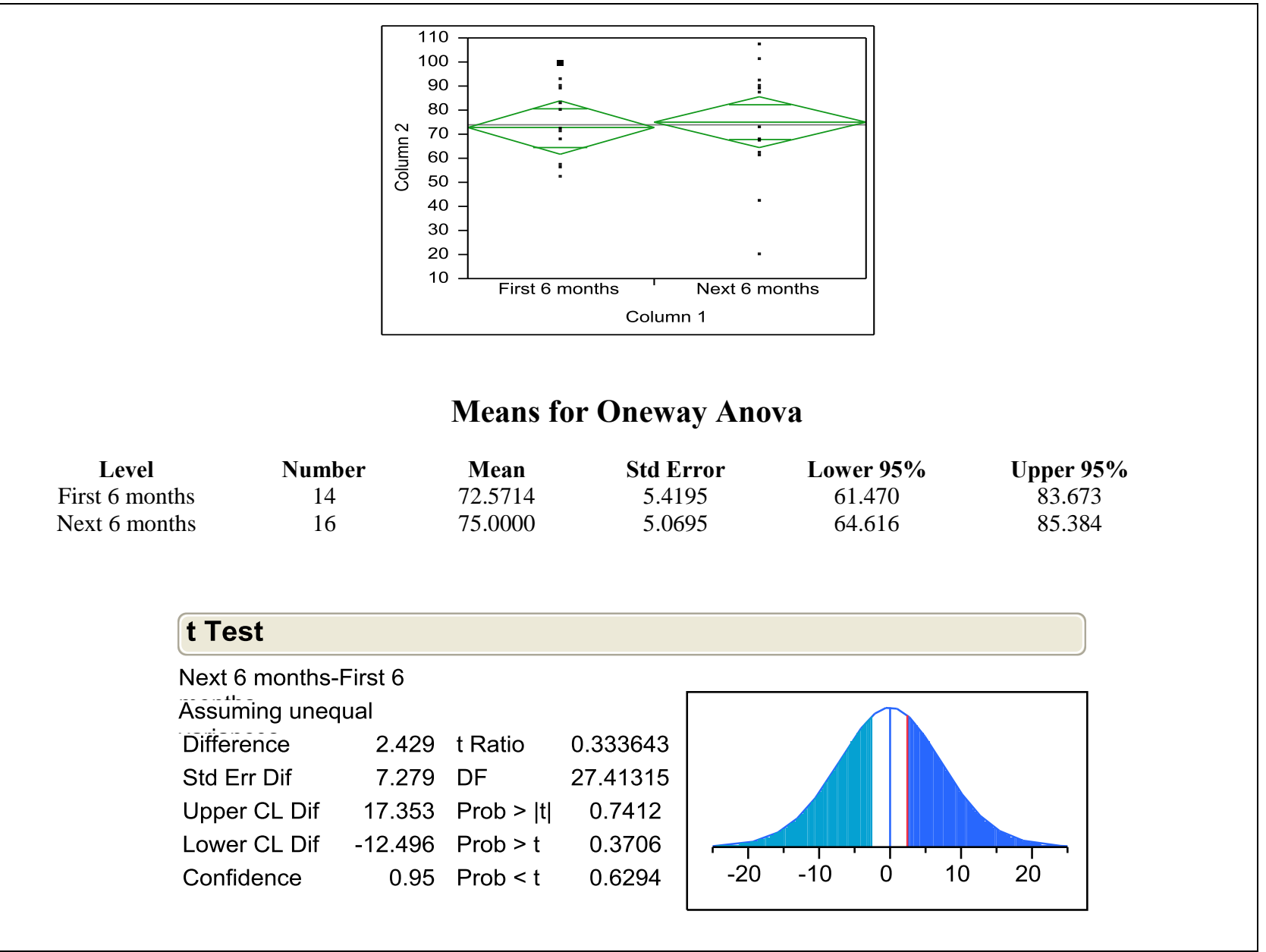

Figure 28: Number of glances away from roadway, 2 or more sec/glance, Novice drivers with first 6 months and next 6 months after license

In the figure above, the t-test analysis shows that the probability of difference between the means of novice drivers with first 6 months and next 6 months of license is $\mathbf{0 . 6 2 9 4}$. This value does not satisfy any confidence level. Therefore, no statistical difference was found between the groups. 
Variable Used: (A) Number of glances away from Roadway

Time Period Considered: (a) More than 2.5 Seconds per Glance

Groups Compared: (1) Unlicensed vs. (3) Experienced Drivers

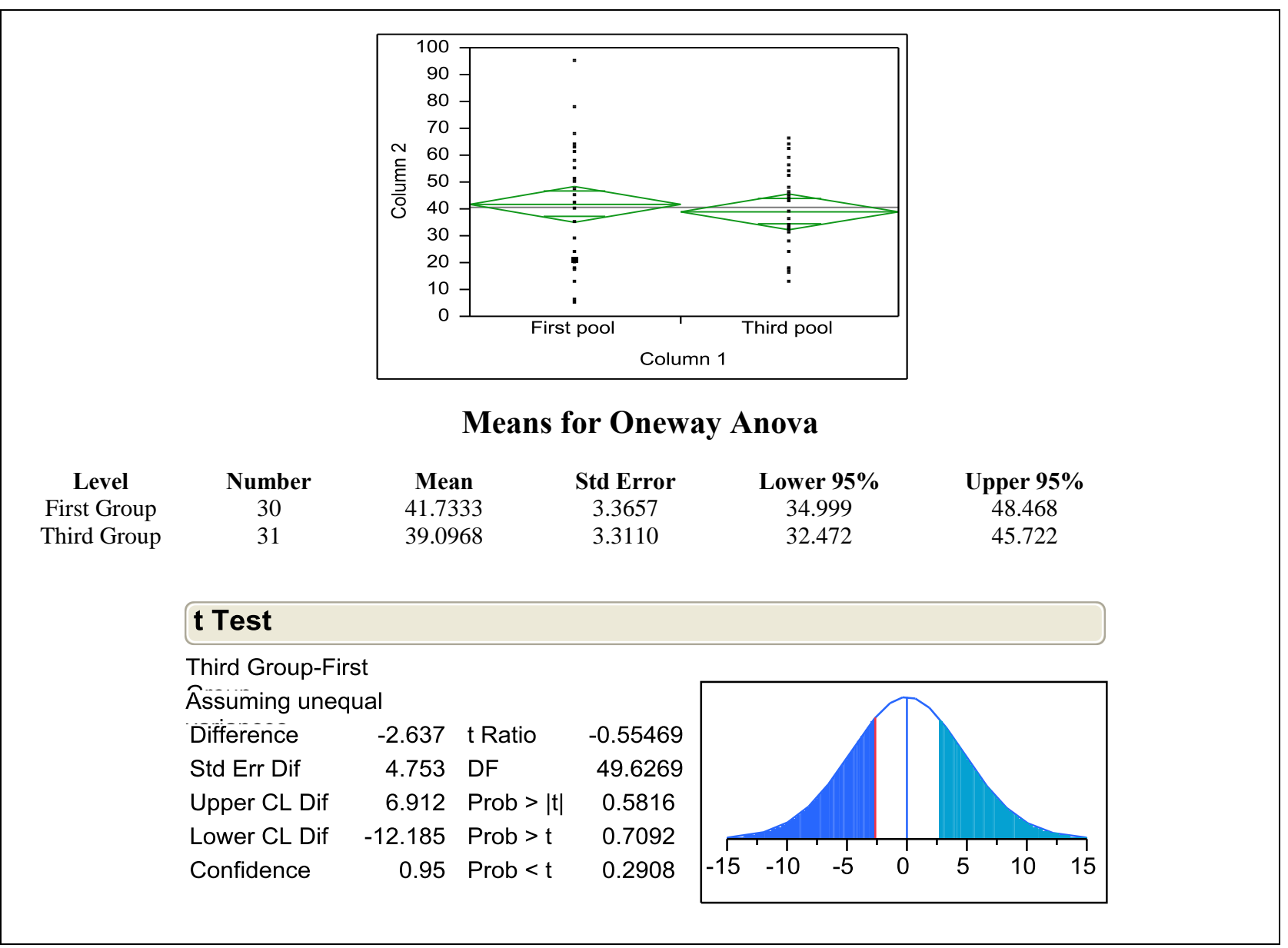

Figure 29: Number of glances away from roadway, 2.5 or more sec/glance, groups (1) \& (3)

In the figure above, the t-test analysis shows that the probability of difference between the means of unlicensed and experienced drivers is $\mathbf{0 . 2 9 0 8}$. This value does not satisfy 95 percent confidence level. Therefore, no statistical difference was found between the groups. 
Variable Used: (A) Number of glances away from Roadway Time Period Considered: (a) More than 2.5 Seconds per Glance Groups Compared: (2) Novice vs. (3) Experienced Drivers

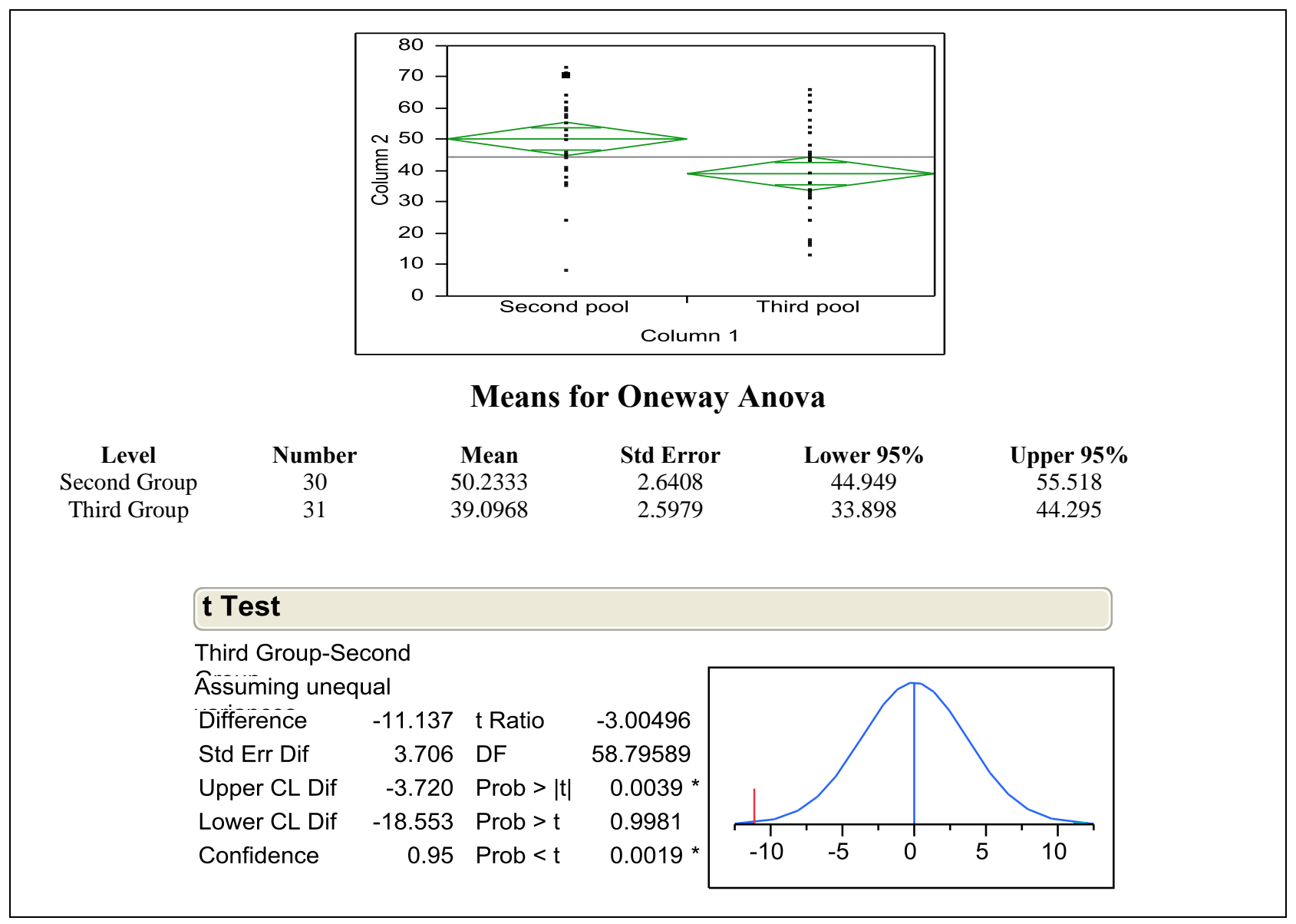

Figure 30: Number of glances away from roadway, 2.5 or more sec/glance, groups (2) \& (3)

In the figure above, the t-test analysis shows that the probability of difference between the means of novice and experienced drivers is $\mathbf{0 . 0 0 1 9}$ and satisfies the 95 percent confidence level. There is strong evidence that the groups are significantly different. 
Variable Used: (A) Number of glances away from Roadway Time Period Considered: (a) More than 2.5 Seconds per Glance Groups Compared: (1) Unlicensed vs. (2) Novice Drivers

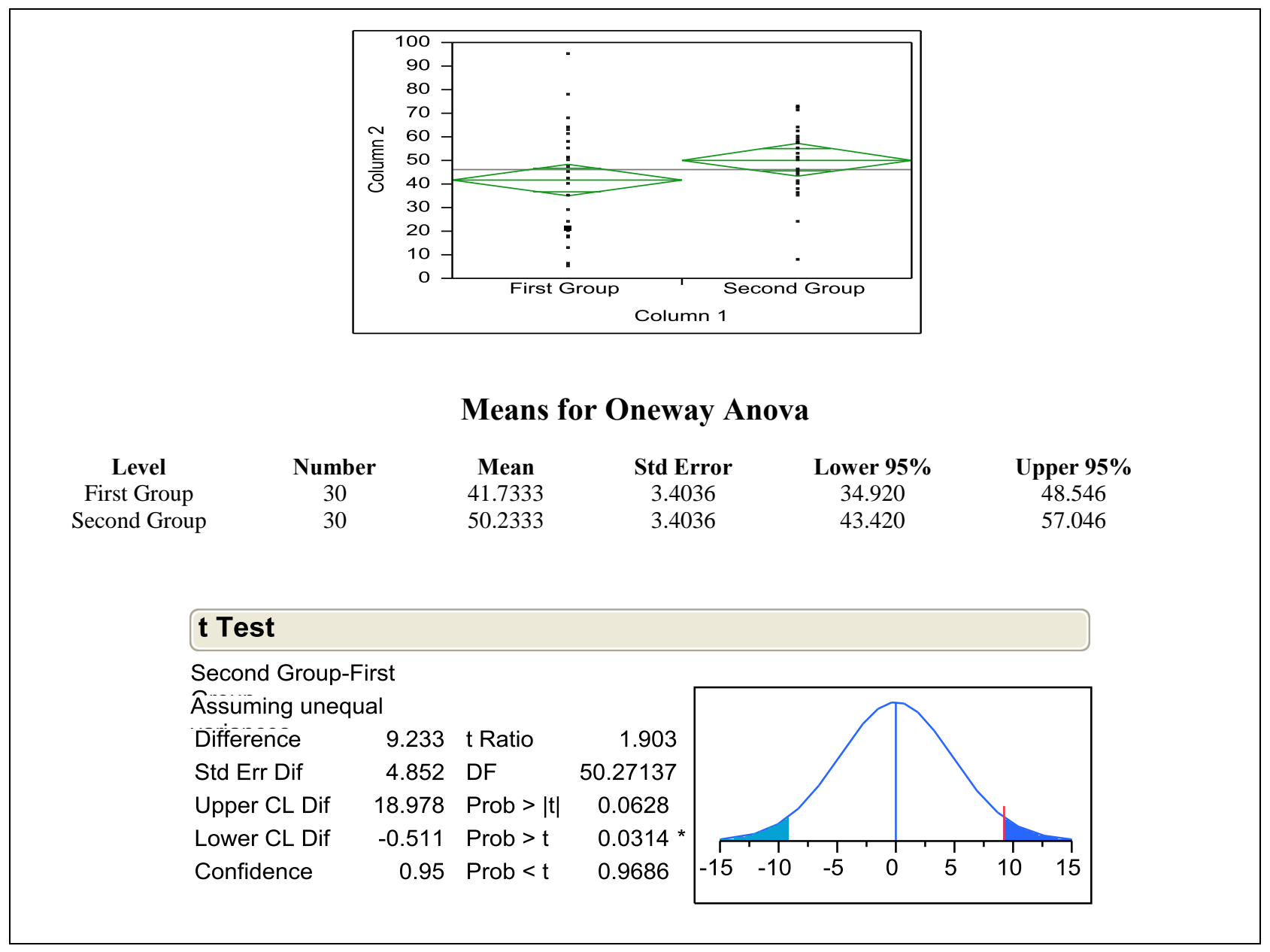

Figure 31: Number of glances away from roadway, 2.5 or more sec/glance, groups (1) \& (2)

In the figure above, the t-test analysis shows that the probability of difference between the means of unlicensed and novice drivers is $\mathbf{0 . 9 6 8 6}$. This value does not satisfy 95 percent confidence level. Therefore, no statistical difference was found between the groups. 
Variable Used: (A) Number of glances away from Roadway Time Period Considered: (a) More than 2.5 Seconds per Glance

Groups Compared: Novice Drivers: First 6 months vs. Next 6 months after License

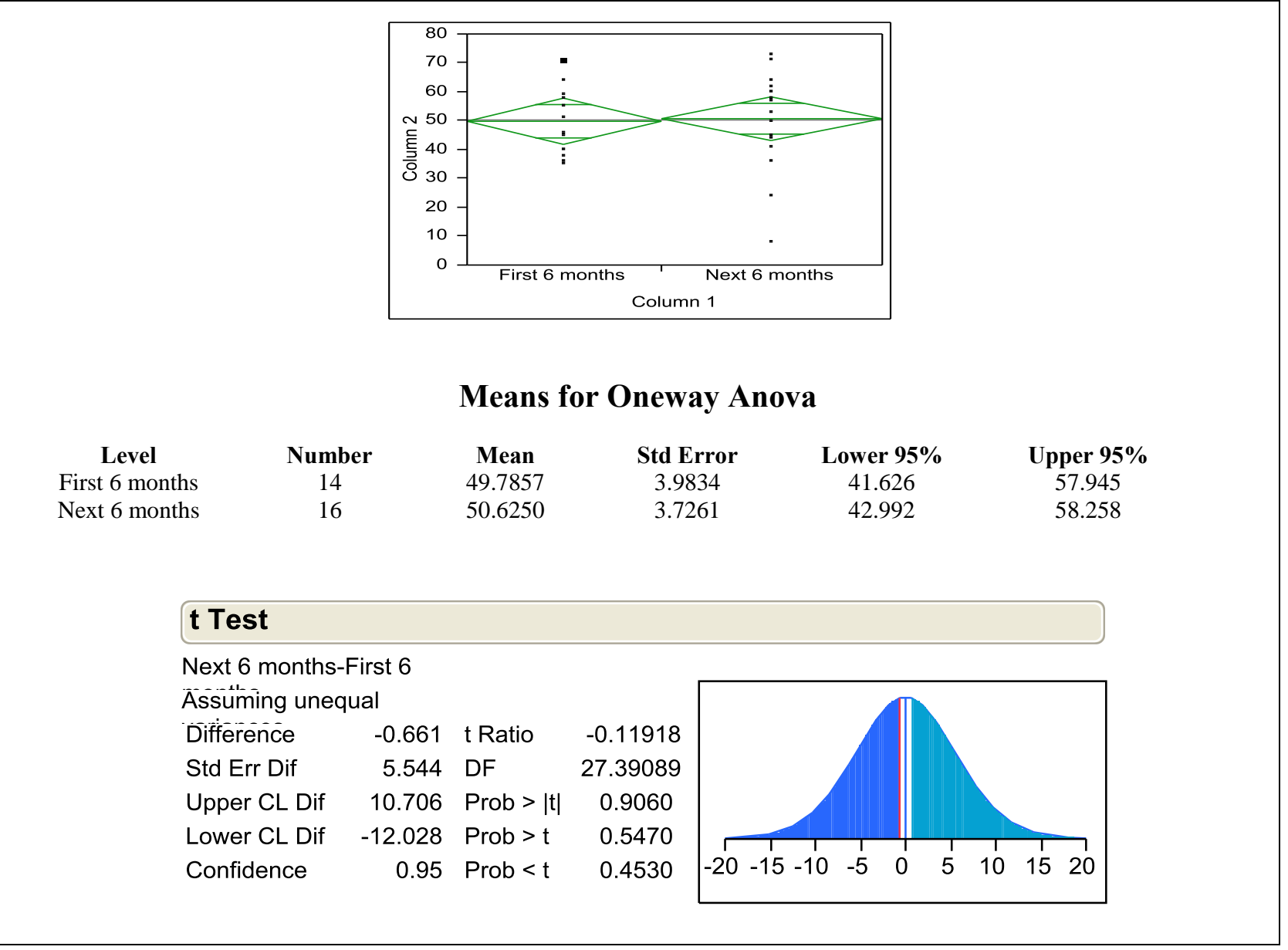

Figure 32: Number of glances away from roadway, 2.5 or more sec/glance, Novice drivers with first 6 months and next 6 months after license

In the figure above, the t-test analysis shows that the probability of difference between the means of novice drivers with first 6 months and next 6 months of license is $\mathbf{0 . 4 5 3 0}$. This value does not satisfy any confidence level. Therefore, no statistical difference was found between the groups. 
Variable Used: (A) Number of glances away from Roadway

Time Period Considered: (a) More than 3 Seconds per Glance

Groups Compared: (1) Unlicensed vs. (3) Experienced Drivers

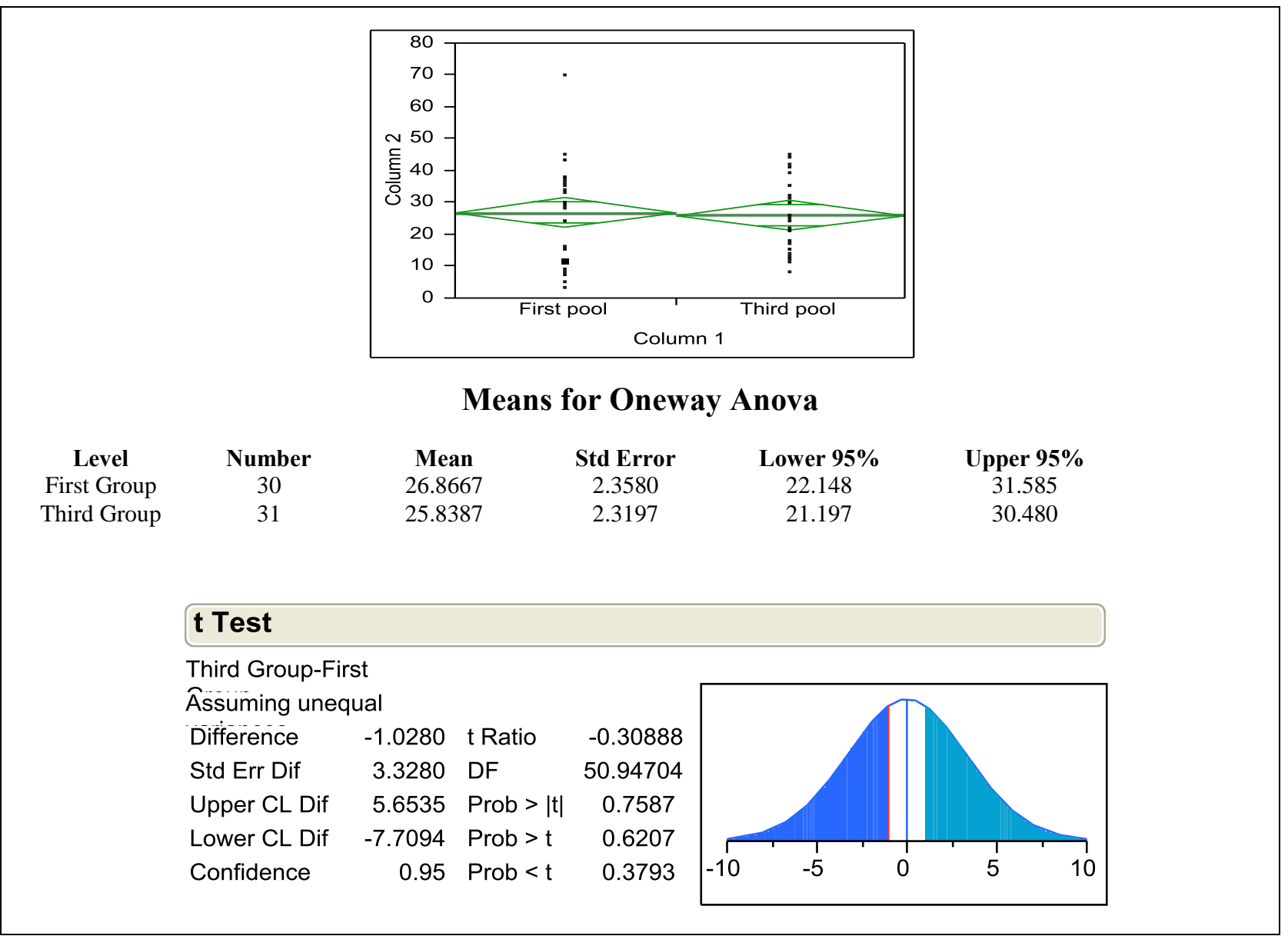

Figure 33: Number of glances away from roadway, 3 or more sec/glance, groups (1) \& (3)

In the figure above, the t-test analysis shows that the probability of difference between the means of unlicensed and experienced drivers is $\mathbf{0 . 3 7 9 3}$. This value does not satisfy 95 percent confidence level. Therefore, no statistical difference was found between the groups. 
Variable Used: (A) Number of glances away from Roadway

Time Period Considered: (a) More than 3 Seconds per Glance

Groups Compared: (2) Novice vs. (3) Experienced Drivers

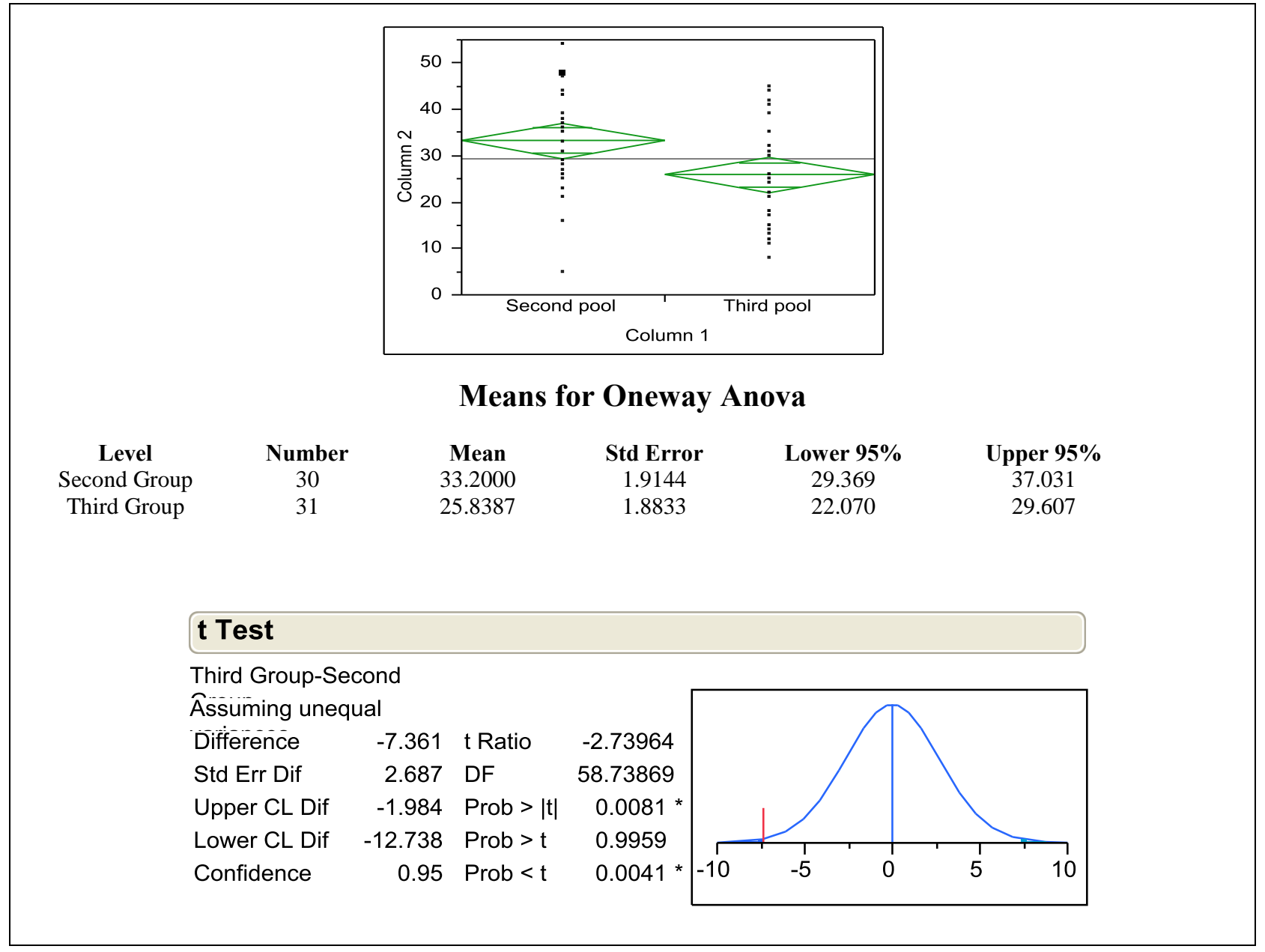

Figure 34: Number of glances away from roadway, 3 or more sec/glance, groups (2) \& (3)

In the figure above, the t-test analysis shows that the probability of difference between the means of novice and experienced drivers is $\mathbf{0 . 0 0 4 1}$ and satisfies the 95 percent confidence level. There is strong evidence that the groups are significantly different. 
Variable Used: (A) Number of glances away from Roadway Time Period Considered: (a) More than 3 Seconds per Glance Groups Compared: (1) Unlicensed vs. (2) Novice Drivers

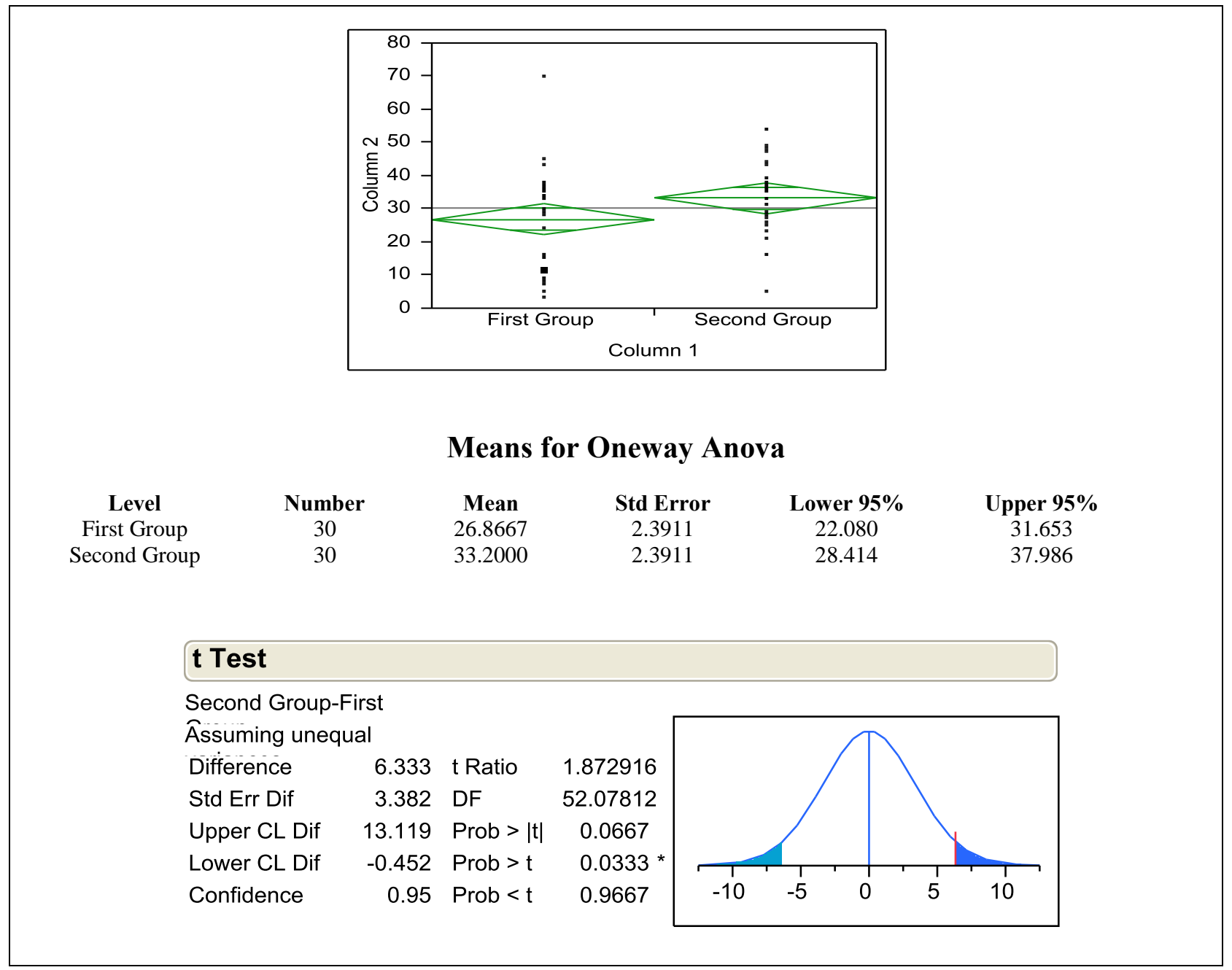

Figure 35: Number of glances away from roadway, 3 or more sec/glance, groups (1) \& (2)

In the figure above, the t-test analysis shows that the probability of difference between the means of unlicensed and novice drivers is $\mathbf{0 . 9 6 6 7}$. This value does not satisfy 95 percent confidence level. Therefore, no statistical difference was found between the groups. 
Variable Used: (A) Number of glances away from Roadway

Time Period Considered: (a) More than 3 Seconds per Glance

Groups Compared: Novice Drivers: First 6 months vs. Next 6 months of License

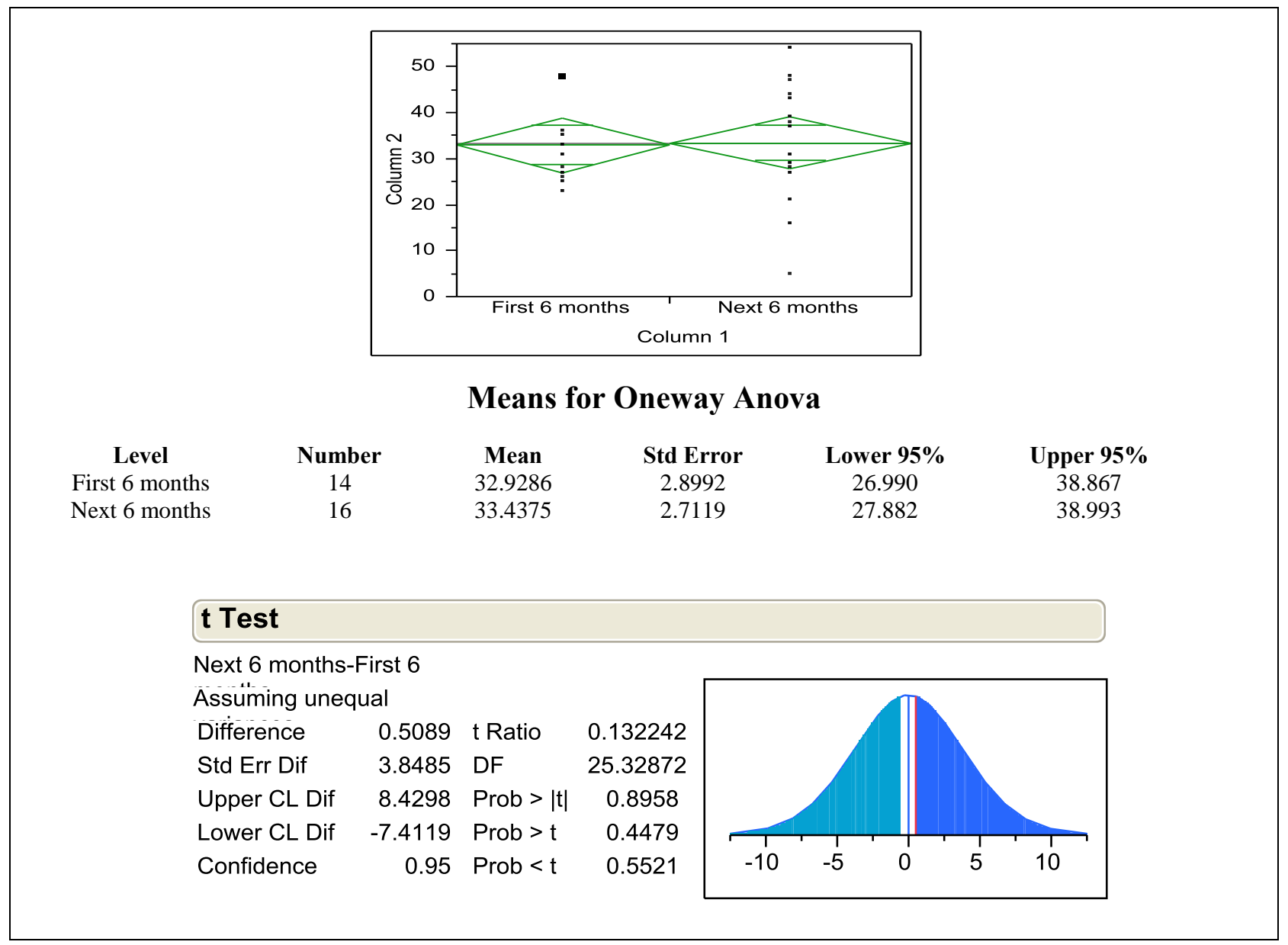

Figure 36: Number of glances away from roadway, 3 or more sec/glance, Novice drivers with first 6 months and next 6 months after license

In the figure above, the t-test analysis shows that the probability of difference between the means of novice drivers with first 6 months and next 6 months of license is $\mathbf{0 . 5 5 2 1}$. This value does not satisfy any confidence level. Therefore, no statistical difference was found between the groups 


\subsection{Summary of Results}

The following table summarizes the results from statistical analysis:

\begin{tabular}{|c|c|c|c|c|}
\hline $\begin{array}{c}\text { Time spent per glance for } \\
\text { more than }\end{array}$ & Comparing & $\begin{array}{c}\text { Total time spent away from } \\
\text { the roadway }\end{array}$ & $\begin{array}{l}\text { Pecentage time spent away } \\
\text { from the roadway }\end{array}$ & $\begin{array}{l}\text { Number of glances away } \\
\text { from the roadway }\end{array}$ \\
\hline 2 seconds & $\begin{array}{l}\text { Groups: (1) vs (3) } \\
\text { Groups: (2) vs (3) } \\
\text { Groups: (1) vs (2) } \\
\text { First } 6 \text { vs Next } 6\end{array}$ & $\begin{array}{l}\text { NO }(p-\text { value }=0.3502) \\
\text { YES }(\mathbf{p}-\text { value }=\mathbf{0 . 0 0 9 1}) \\
\text { NO }(p \text {-value }=0.9200) \\
\text { NO }(p-\text { value }=0.6011)\end{array}$ & $\begin{array}{l}\text { NO }(p-\text { value }=0.7465) \\
\text { YES }(\mathbf{p}-\text { value }=\mathbf{0 . 0 4 2 8}) \\
\text { NO }(p \text {-value }=0.9837) \\
\text { NO }(p \text {-value }=0.7519)\end{array}$ & $\begin{array}{l}\text { NO }(p-\text { value }=0.4135) \\
\text { YES }(\mathbf{p}-\text { value }=\mathbf{0 . 0 1 4 6}) \\
\text { NO }(p-\text { value }=0.9212) \\
\text { NO }(p-\text { value }=0.6294)\end{array}$ \\
\hline 2.5 seconds & $\begin{array}{l}\text { Groups: (1) vs (3) } \\
\text { Groups: (2) vs (3) } \\
\text { Groups: (1) vs (2) } \\
\text { First } 6 \text { vs Next } 6\end{array}$ & $\begin{array}{l}\text { NO }(p \text {-value }=0.2680) \\
\text { YES }(\mathbf{p} \text {-value }=\mathbf{0 . 0 0 2 3}) \\
\text { NO }(p \text {-value }=0.9456) \\
\text { NO }(p \text {-value }=0.5606)\end{array}$ & $\begin{array}{l}\text { NO }(p \text {-value }=0.6036) \\
\text { YES }(\mathbf{p} \text {-value }=\mathbf{0 . 0 1 1 5}) \\
\text { NO }(p \text {-value }=0.9863) \\
\text { NO }(p \text {-value }=0.5324)\end{array}$ & $\begin{array}{l}\text { NO }(p \text {-value }=0.2908) \\
\text { YES }(\mathbf{p} \text {-value }=\mathbf{0 . 0 0 1 9}) \\
\text { NO }(p \text {-value }=0.9686) \\
\text { NO }(p \text {-value }=0.4530)\end{array}$ \\
\hline 3 seconds & $\begin{array}{l}\text { Groups: (1) vs (3) } \\
\text { Groups: (2) vs (3) } \\
\text { Groups: (1) vs ( } 2) \\
\text { First } 6 \text { vs Next } 6\end{array}$ & $\begin{array}{l}\text { NO }(p-\text {-value }=0.3204) \\
\text { YES }(\mathbf{p} \text {-value }=\mathbf{0 . 0 0 4 0}) \\
\text { NO }(p-\text { value }=0.9529) \\
\text { NO }(p-\text { value }=0.5998)\end{array}$ & $\begin{array}{l}\text { NO }(p-\text {-value }=0.6072) \\
\text { YES }(\mathbf{p} \text {-value }=\mathbf{0 . 0 1 5 3}) \\
\text { NO }(p \text {-value }=0.9817) \\
\text { NO }(p \text {-value }=0.6408)\end{array}$ & $\begin{array}{l}\text { NO }(p-\text { value }=0.3793) \\
\text { YES }(\mathbf{p} \text {-value }=\mathbf{0 . 0 0 4 1}) \\
\text { NO }(p-\text { value }=0.9667) \\
\text { NO }(p-\text { value }=0.5521)\end{array}$ \\
\hline
\end{tabular}


The above results obtained from t-test analysis give the probability of difference between the groups; the analysis will be discussed below.

Firstly, there is a significant difference found between novice drivers (Group 2) and experienced drivers (Group 3). The difference is found in all the three variables discussed above in correspondence to all glance durations in the analysis. The difference is found to be significant at a confidence level of 95 percent. Significant difference is not found between other groups such as unlicensed (Group 1) and experienced (Group 3), unlicensed (Group 1) and novice (Group 2) and drivers within first 6 months and next 6 months after licensure. 


\section{CONCLUSIONS}

This research has found evidence suggesting a significant difference between novice and experienced drivers with respect to all the three variables: total glance duration away from the roadway, percentage time looking away from the roadway, and number of glances away from the roadway. The previous phase of this research was performed considering glances of any time duration (i.e. greater than $1 / 60^{\text {th }}$ of a second) and concluded that novice and experienced drivers spent a similar percentage of time looking at the center of the roadway (i.e. no significant difference was found). However, the number of glances away from the roadway was significantly different. Novice drivers make fewer glances away from the center compared to experienced drivers. This research found that novice drivers make fewer, but relatively long, glances away from the center while experienced drivers make numerous short glances away from road, scanning their surroundings and traffic environment while driving. This was true for all three time periods: glances greater than 2, 2.5 and 3 seconds.

Unlicensed or GDL drivers' performance was similar in general to experienced drivers, but with a considerable variability. They resembled experienced driving, doing what they were supposed to: scanning surroundings thoroughly. The considerable large standard deviation found in this group though, did not facilitate in achieving a significant difference between young and novice drivers. The reason behind this near-perfect performance is due to the presence of an instructor in the vehicle. This authoritative figure guided the high school students, with dissimilar experience, along the roadway. The performance of unlicensed drivers emphasizes the success of the GDL program. 
In the literature, previous research has found significant change in the scanning abilities of novice drivers with experience of more than 6 months compared to less than 6 months. However in this research, the analysis of novice drivers within first 6 months of licensed driving and more than 6 months after licensed driving (7-12 months) showed no significant difference in terms of distraction. 


\section{RECOMMENDATIONS}

This research involved GDL drivers, novice drivers within their first year of licensed driving, and experienced drivers with four years of more driving experience. In order to track the development in driving behavior in relation to distraction, drivers with more than one year but less than five years of experience are recommended for future research. Most importantly, recent trends show the increase in crash involvement by drivers of 65 years or more. Such increase may be due to the increase in work load in older population, but most likely is related to the increase of perception-reaction time, failure to identify hazards due to slower visual information processing usually observed among older drivers. In order to evaluate and understand distraction in older drivers, future research in this direction is recommended. 


\section{REFERENCES}

1. Akuraju, N (2009). "Assessing the Variation of Driver Distraction with Experience". Unpublished MS Thesis, West Virginia University, Morgantown, WV.

2. Bach, K.H., Jaeger, M.G., Skov, M.B., \& Thomassen, N.G. (2008). Evaluating Driver attention and Driving Behavior: Comparing Controlled Diving and Simulated Driving. British Computer Society, Vol 1, 193-201.

3. Baxter, J.S., Manstead, A.S.R., Stradling, S.G., Campbell, K.A., Reason, J.T., \&Parker, P. (1990). Social Facilitation and driver behavior. British Journal of Psychology, 81, 351-360.

4. Beijer, D. (2003). Observed Driver Glance Behavior at Roadside Advertising. (2003). Transportation research Board Annual meeting, 2004.

5. Beirness, D,J., Simpson, H.M., \& Pak, A. (2002). The Road safety Monitor: Driver Distraction. Traffic Injury Research Foundation. Ontario, Canada.

6. Bottom, C.G., \& Ashworth, R. (1978). Factors affecting the variability of driver gap acceptance behavior, Ergonomics, 21, 721-734.

7. Brackstone, M., \& Waterson, B. (2003). Are We Looking Where we are Going? An Explanatory Examination of Eye Movement in High Speed Driving. TRB 2004 Annual Meeting.

8. Brown, I.D., \& Groeger, J.A.(1988). Risk Perception and decision taking during the transition between novice and experienced driver status. Ergonomics, 31, 585-597.

9. Clarke, D.D., Ward, \&Truman, W. (2005). Voluntary risk taking and skill deficits in young driver accidents in the UK. Accident Analysis and Prevention, 37(3), 523-529.

10. Crundall, D., Underwood, G., \& Chapman, P. (1999). Driving Experience and functional field of view. Perception, Vol 28, pages 1078-1087.

11. Curry, R., Greenburg, J., \& Blanco, M. (2002). An Alternate method to measure driver distraction. Intelligent Transportation Society of America's $12^{\text {th }}$ Annual Meeting and Exposition, USA.

12. Dewar, R.E., \& Olson, P.L. (2001). Human factors in Traffic Safety.

13. Donmez, B., Boyle, L.N., \& Lee, J.D. (2010). Differences in off-road glances: The effects on young driver's performance. Journal of Transportation Engineering, Vol 136, No.5, pp. 403409.

14. Elander, J. West, R. \& French, D. (1993). Behavioral correlates of individual differences in road crash risk: An examination of methods and findings. Psychological Bulletin, 113, 279294.

15. Evans, L., \& Wasielewski, P. (1983). Risky driving related to driver and vehicle characteristics. Accident Analysis and Prevention, 15, 121-136. 
16. Farber, E., Foley, J., \& Scott, S. (2000). Visual attention design limits for ITS in-vehicle systems: The Society of Automotive Engineers standard for limiting visual distraction while driving. TRB Annual General Meeting, Washington DC.

17. Galin, D. (1981). Speeds on two-lane rural roads: a multiple regression analysis. Traffic Engineering and Control, 22, 433-460.

18. Glaze, A.L., \& Ellis, J.M. (2003). Pilot study of distracted drivers. Report prepared for Virginia Commonwealth University, Transportation and Safety Training Centre, VA, USA.

19. Haigney, D., \& Westerman, S.J. (2001). Mobile phone use while driving: a critical review of research methodology. Ergonomics, 44, 132-143.

20. Hedlund, J., Shultz, R., \& Compton, R. (2003). What we know, what we don't know, and what we need to know about graduated driver licensing, Journal of Safety Research, 34, 107115.

21. Ito, H., Uno, H., Atsumi, B., \& Akamatsu, M. (2001). Visual distraction while driving: Trends in research and standardization, IATSS Research, 25, 20-28.

22. Laberge, J., Scialfa, C., White, C., \& Caird, J.(2003). The Effect of Passenger and Cellphone Conversations on Driver distraction. Transportation Research Board 2004 Annual Meeting.

23. Lamble, D., Laasko, M., \& Summala, H.(1999). Detection Thresholds in car following situations and peripheral vision: Implications for positioning of visually demanding in-car displays. Ergonomics, 42(6), 807-815.

24. Lesch, M.F., \& Hancock, P.A. (2004). Driving Performance during concurrent cell-phone use: are drivers aware of their performance decrements? Accident Analysis and Prevention, 35, 441-450.

25. Lin, M-L., \& Fearn, K.T.(2003). The provisional license: nighttime and passenger restrictions -a literature review. Journal of Safety Research, 34, 51-61.

26. Liu, Bor-Shong, \& Lee, Yung-Hui. (2006), In-vehicle workload assessment: Effects of traffic situations and cellular phone use. Journal of safety Research, 37, 99-105.

27. McKenna, F.P., Waylen, A.E., \& Burkes, M.E. (1998). Male and female drivers: how different are they? Berkshire, UK: The University of Reading, Foundation for road safety research.

28. McKnight, A.J., \& McKnight, K.S. (2000). The Behavioral contributors to highway crashes of youthful drivers. Proceedings of $44^{\text {th }}$ annual conference of the Association of the Advancement of Automotive Medicine (pp. 321-346). Des Plaines, IL

29. McKnight, A.J., \& McKnight, A.S. (2003). Young Novice drivers careless or clueless. Accident Analysis and Prevention, Vol 35, Issue 6, 921-925.

30. Mourant, R.R., \& Rockwell, T.H. (1972). Strategies of visual search by novice and experienced drivers, Human Factors, 14, 325-335.

31. Neale, V L; Dingus, T A; Klauer, S G; Sudweeks, J; Goodman, M. (2005) An Overview of the 100-Car Naturalistic Study and Findings. www.nhtsa.gov.

32. Olsen, E.C.B., Lee, S.E., \&Simons-Morton, G. (2007). Eye Movement Patterns for Novice Teen Drivers Does 6 months of Driving Experience Make a Difference? 
33. Peters, G.A., \& Peters, B.J.(2001). The distracted driver. The Journal of the Royal Society for the Promotion of Health, 121, 23-28.

34. Pradhan, A.K., Hammel, K.R., DeRamus, R., Pollatsek, A., Noyce, D.A., \& Fisher, D.L. (2005). Using eye movement to evaluate effects of driver age on risk perception ina driving simulator. Human Factors, 47(4), 840-852.

35. Quimby, A.R., \& Watts, G.R., (1981). Human factors and driving performance, Report no. RR1004, Crowthorne, Berkshire: Transport and Road Research Laboratory.

36. Ranney, T.A., Mazzae, E., Garrott, R., \& Goodman, M.J. (2000). NHTSA Driver Distraction Research: Past, Present and Future.

37. Regan, M.A., Lee, J.D., \& Young, K.L. (2009). Driver Distraction: Theory, effects and Mitigation. CRC Press, Taylor and Francis Group. ISBN: 978-0- 8493-7426-5.

38. Rockwell, T.H. (1988). Spare visual capacity in driving - revisited: New empirical results for an old idea. Vision in vehicles II, A.G. Gale et al editors, Elsevier Science Publishers BV.

39. Senders, J. W., Kristofferson, A. B., Levison, W. H., Dietrich, C. W., \& Ward, J.L.(1967). The attentional demand of automobile driving. Highway research Board, 195, 15-33.

40. Smiley, A., Smahel, T., \& Eizenman, M. (2003). The Impact of Video Advertising on Driver Fixation Patterns. TRB 2004 Annual Meeting.

41. Steff, F.M., \& Spradlin, H.K. (2000). Driver distraction, aggression and fatigue: A synthesis of the literature and guidelines for Michigan planning (Report UMTRI-2000-10). Ann Arbor, MI: The University of Michigan Transport Research Institute.

42. Stutts, J.C., Reinfur, D.W., Staplin, L. W., \& Rodgman, E.A. (2001). The role of driver distraction in traffic crashes. Washington, DC: AAA Foundation for Traffic Safety.

43. Treat, J.R. (1980). A study of pre-crash factors involved in traffic accidents. HSRI Research review, Vol 10, 1-35.

44. Trent, V.W. (2005). Sensitivity of eye-movement measures to in-vehicle task difficulty, Transportation Research, Part F, Traffic psychology and behavior, Vol 8 No.2, pp. 167-190.

45. White, M.P., Eiser, J.R., \& Harris, P.R. (2004). Risk Perceptions of mobile phone use while driving. Risk Analysis, 24, 323-333.

46. Wickens, C.D. (2002). Multiple resources and performance prediction. Theoretical Issues in Ergonomics Science, 3, 159-177.

47. Wikman, A., Nieminen, T. \& Summala, H. (1998). Driving experience and time sharing during in-car tasks on roads of different width. Ergonomics, 41:3, 358-372.

48. www-nrd.nhtsa.dot.gov/CATS/index.aspx (2009). An Examination of Driver Distraction as Recorded in NHTSA databases, Traffic Safety Facts, DOT HS 811216.

49. Zwahlen, H.T. (1988). Safety aspects of cellular telephones in automobiles. International Symposium on Automotive Technology and Automation (ISATA), Paper No: 88058). 